\title{
Incentivizing Irreversible Investment
}

\author{
Dmitry Livdan \\ Alexander Nezlobin* \\ Haas School of Business, \\ London School of Economics \\ University of California, Berkeley \\ a.nezlobin@lse.ac.uk \\ livdan@haas.berkeley.edu
}




\begin{abstract}
Existing dynamic investment models that show that a manager can be incentivized to implement the optimal investment policy rely on the assumption that the firm is operating in an ever-expanding product market. This paper presents an analytically tractable, discrete-time, neoclassical model with irreversible investment and the possibility of unfavorable demand events. We show that even when the principal is uninformed about changes in demand for the firm's output, there exists a performance measurement system that leads to goal congruent investment incentives for the manager. If the principal can observe the unfavorable demand events, then goal congruence can be achieved using very simple accrual accounting rules, such as straight-line depreciation.
\end{abstract}

Keywords: Irreversible investment, goal congruence, performance measurement, residual income.

JEL Codes: G31, M41, M52. 


\section{INTRODUCTION}

Rogerson (2008) shows that if capital goods are valued at their (hypothetical) replacement cost, then a manager who is compensated based on the firm's residual income has the incentives to make the fully optimal sequence of investments. An important assumption of that paper is that the firm is operating in an ever-expanding product market, that is, that there are no unfavorable shocks to demand for the firm's product. It is, however, well-known that if investments are irreversible, then the possibility of unfavorable demand events drastically changes the nature of the firm's optimal investment policy. This observation is often referred to as the Bernanke's (1983) "bad news" principle. In this paper, we present an analytically tractable variant of Rogerson's (2008) model that allows for the possibility of unfavorable shocks to demand for the firm's output and demonstrate how goal congruence can be attained within the realm of the bad news principle.

Models with irreversible investment and stochastic demand are among the most commonly used in the economics and finance literature. ${ }^{1}$ In such models, the firm dynamically adjusts its capital stock to the prevailing product market conditions. The firm can increase its productive capacity by purchasing new capital goods if demand improves but is usually assumed to be unable to sell its existing assets if the product market contracts - this latter assumption is referred to as investment irreversibility. Since the firm's reaction to the resolution of uncertainty is constrained on the downside, i.e., in the case of bad news about the product market, the investment problem in such models is of the option-like type. Anticipating the possible future bad news to which it will not be able to respond, the firm becomes more reluctant to invest even in good states of nature. ${ }^{2}$ As a consequence, one of

\footnotetext{
${ }^{1}$ For an overview of such models (see, e.g., Dixit and Pindyck 1994). The term irreversible investment is usually applied broadly to both tangible and intangible firm- or industry-specific investment. While expenditures on intangibles are often not treated as investments for financial reporting purposes, it is common to treat them as such for the purposes of managerial performance evaluation.

${ }^{2}$ Intuitively, at each possible investment date, the firm internalizes (together with the direct cost of investment) the expected future cost of binding irreversibility constraints. Since such constraints bind only in the bad states of nature, it is the probability of such future bad states that drives up the shadow cost of capital.
} 
the attractive features of irreversible investment models is that they explain lumpiness in investment observed in the data.

Most existing irreversible investment models are analytically tractable only in continuous time and under the restrictive assumptions of an infinite useful life of capital goods and geometrically declining productive efficiency. In contrast, when the possibility of bad news is assumed away, Rogerson (2008) demonstrates that the investment problem can be solved in closed form for capital goods with arbitrary useful lives and efficiency profiles. ${ }^{3}$ In this paper, we develop a variant of Rogerson's (2008) model that admits closed-form characterizations of the firm's optimal investment policy and its equity value. Specifically, we assume that, in each period, the firm can either have monopoly (pricing) power in its product market or be a price-taker forced to sell its output at a price below its long-run marginal cost of production. The availability of pricing power is governed by a regime-switching Markov process. Effectively, the firm can be thought of as participating in two product markets: premium, in which the firm can price its product; and generic, in which the firm is a pricetaker. The firm's access to the premium market is intermittent. For analytical tractability, we assume that the premium market is weakly expanding over time, even when the firm is shut out of it.

We show that in the setting described above, the firm's optimal investment policy is characterized by two conditions, the first one of which is that the firm should never invest in the competitive regime (when it does not have pricing power). The second condition is that, in the monopoly regime, the firm invests so as to equate its next period's expected marginal revenue to a certain threshold, often referred to as the user cost of capital. We derive a closed-form expression for the user cost of capital for assets with arbitrary efficiency profiles and show that it exceeds the user cost of capital from Rogerson (2008). Accordingly, the firm invests less in our model with possible bad news than it does in Rogerson's (2008) setting with an expanding product market. The firm's optimal investment policy exhibits

\footnotetext{
${ }^{3}$ Rogerson's (2008) argument would also apply in a setting with possible unfavorable shocks do demand but with fully reversible investment.
} 
two features consistent with the earlier literature on irreversible investment. First, the user cost of capital is increasing - and investment is decreasing - in the likelihood and severity of bad events, as measured by the probability of the competitive regime and the output price in that regime. ${ }^{4}$ Second, the investment policy is lumpy in the sense that it is characterized by intermittent periods of zero and strictly positive investment.

We assume that the principal delegates investment decisions to a better informed manager. The principal does not know whether the firm is currently in the competitive or monopoly regime, and, if it is in the monopoly regime, the principal does not observe the current size of the output market. By way of contrast, the manager observes both the current regime and the product market size. The principal seeks to provide incentives for the manager to implement the first-best investment policy. An additional complication is that the principal has imperfect information about the manager's utility function. It is common knowledge that the manager prefers a higher value of the performance measure to a lower one in each period, but the manager's personal discount factor is unknown to the principal. As is standard in the goal congruence literature, the objective of the principal is to design an accrual accounting rule and a performance based on accounting information that has the property that the optimal investment policy maximizes the performance measure on a period-by-period basis. ${ }^{5}$

The main finding of the paper is that goal congruence is attainable even when the principal is completely uninformed about the product market conditions. The following perfor-

\footnotetext{
${ }^{4}$ To be sure, the user cost of capital is not affected by the magnitude of good events in our model, as measured, for example, by the demand growth rate in the monopoly regime. Furthermore, the user cost of capital would not be increasing in the probability of the competitive regime if the output price in that regime were exactly equal to the long-run production cost of the product, i.e., if the bad events were only neutral.

${ }^{5}$ See, for instance, Rogerson (1997), Reichelstein (1997), Dutta and Reichelstein (2005), Rogerson (2008), Dutta and Reichelstein (2010). Dutta (2007) provides a survey of this literature. There are multiple differences between the goal congruence solution concept and the traditional notion of the second best contract used in the agency literature. For example, while the goal congruence framework largely ignores agency costs, it imposes much weaker assumptions on the principal's information about the agent's utility function and usually allows for starker information asymmetry between the principal and the agent. Reichelstein (2000) combines the goal congruence framework with an explicit agency problem. For a dynamic agency model allowing for investment irreversibility, see DeMarzo and Fishman (2007).
} 
mance evaluation system incentivizes the manager to make the optimal investment decisions: residual income combined with a depreciation policy that we term the relative anticipated marginal benefit (RAMB) rule. To construct this rule, the principal first calculates how the present value of each investment's expected marginal benefits changes over its useful life assuming that the investment was made in the monopoly regime, was made optimally, and will be followed by optimal investments in the future. Under these assumptions, the present value of the anticipated marginal benefits of each investment is equal to its marginal cost at each investment event. ${ }^{6}$ Consequently, when a new capital good is purchased, it is capitalized at its acquisition cost. From that point on, the book value of the capital good declines in proportion to the present value of its remaining expected marginal benefits, where the expectations are always taken from the perspective of the asset acquisition date. In several special cases, we show that the RAMB rule is more conservative than the depreciation policy described in Rogerson (2008). Under this more conservative rule, the manager internalizes the expected cost of future, possibly binding, irreversibility constraints and implements investment decisions that are optimal in the presence of bad news.

We next demonstrate that the problem of goal congruent performance measurement simplifies considerably if the principal is partially informed. Specifically, we consider a setting in which the principal directly observes the bad states of the world in which zero investment is optimal. Then, all that remains is to incentivize the manager to make optimal investments in goods states, i.e., when the firm the monopoly regime. We show that this can be accomplished even with very straightforward accounting rules. For instance, if the cost of each capital good is allocated to the periods of its useful life in simple proportion to its efficiency, then it suffices for the principal to appropriately scale up the aggregate depreciation expense in the calculation of the firm's net income. The use of this performance measure in periods in which the firm has pricing power, combined with setting the performance measure to zero

\footnotetext{
${ }^{6}$ In our model, as in Rogerson (2008), the principal does not have enough information to calculate the expected value of the investment benefits at each future date, yet the principal can calculate the expected value of the marginal investment benefits assuming that the firm follows the optimal investment policy.
} 
in all other periods, is then shown to achieve goal congruence. Lastly, we show that the main results of the paper are not driven by our assumed regime-switching structure of the product market and readily carry over to a model with more traditional stochastic demand formulation. In this variant of our model, however, we have to restrict attention to capital goods with geometric efficiency.

Our paper contributes to the growing literature in accounting that uses real options models to study questions in incentive provision and product costing and pricing decisions (e.g., Arya and Glover 2001; Pfeiffer and Schneider 2007; Caskey and Hughes 2012; Johnson, Pfeiffer, and Schneider 2013; Reichelstein and Rohlfing-Bastian 2015; Baldenius, Nezlobin, and Vaysman 2016, Johnson and Pfeiffer 2016; Johnson, Pfeiffer, and Schneider 2017; Reichelstein and Sahoo 2018). ${ }^{7}$ Perhaps, the paper closest to ours from this stream of literature is Baldenius et al. (2016), which shows that goal congruence is not attainable in a model where the firm's manager is responsible for timing a single binary investment decision. In contrast, in our setting with repeated investments, which also need to be optimally timed, goal congruence is achievable even when the principal is uninformed about the current conditions in the firm's output market. Whereas the main trade-off - to make an investment now or to postpone it to a future date - is the same in both papers, the option to wait affects this trade-off as a lump sum amount when the investment decision is discrete, but as a marginal amount when each investment decision is continuous. In Baldenius et al. (2016), the total value of the option to wait from the manager's perspective depends on the manager's personal discount factor and is, therefore, unknown to the principal. In contrast, in our model, the marginal value of the option to wait is a commonly known constant. This latter result obtains because the demand specifications we consider allow for a simple characterization of the optimal investment policy in terms of a constant user cost of capital, which leads to a constant marginal value of the option to wait on the optimal investment path.

\footnotetext{
${ }^{7}$ Accounting-based equity valuation models with real options can be found in Zhang (2000) and Livdan and Nezlobin (2017).
} 


\section{MODEL SETUP}

Our analysis builds on the framework of Rogerson (2008), which has been used in several studies on dynamic performance measurement (e.g., Dutta and Reichelstein 2010; Nezlobin, Reichelstein, and Wang 2015). ${ }^{8}$ Consider a firm that makes repeated investments in a single type of capital goods (assets). The firm is all-equity financed and all cash flows are disbursed to, or supplied by, the firm's owner immediately. A unit of the capital good costs exactly one dollar and, if purchased in period $t$, generates $x_{\tau}$ units of productive capacity in period $t+\tau$ for $\tau \geq 1$. Note that capital goods begin generating useful capacity one period after their acquisition. Let $T$ denote the length of the useful life of capital goods, so that $x_{T+1}=0$. We normalize the productive capacity of new capital goods to one and assume that the productivity of assets weakly declines with their age:

$$
1=x_{1} \geq \ldots \geq x_{T}
$$

We will refer to the vector $\boldsymbol{x}=\left(x_{1}, \ldots, x_{T}\right)$ as the efficiency pattern of the firm's assets.

Let $I_{t}$ denote the number of units of the capital good purchased in period $t$. Since each unit costs a dollar, $I_{t}$ is also the firm's investment cash outflow in period $t$. The firm's total productive capacity, or capital stock, in period $t$ is then given by:

$$
K_{t}=\sum_{\tau=1}^{T} x_{\tau} \cdot I_{t-\tau},
$$

The vector $\Theta_{t} \equiv\left(I_{t-1}, \ldots, I_{t-T}\right)$ will be referred to as the firm's relevant investment history in period $t$.

One efficiency pattern that has been most commonly studied in the earlier literature is that of geometric efficiency. In this special case, the useful life of capital goods is infinite,

\footnotetext{
${ }^{8}$ Rogerson's (2008) framework has also been used in studies on equity valuation, rate-of-return regulation, and financial statement analysis. See, for instance, Rajan and Reichelstein (2009), Rogerson (2011), Nezlobin, Rajan, and Reichelstein (2012), McNichols, Rajan, and Reichelstein (2014), Nezlobin, Rajan, and Reichelstein (2016), Reichelstein and Sahoo (2017).
} 
$T=\infty$, and their productive capacity declines geometrically with age:

$$
x_{\tau}=(1-\delta)^{\tau-1}
$$

for some $0 \leq \delta \leq 1$. Then, the vintage composition of the firm's assets-in-place does not play a role for future investment decisions, and one obtains the usual law of motion for the firm's capital stock:

$$
K_{t+1}=(1-\delta) K_{t}+I_{t}
$$

In our model, the firm cannot sell its used assets if the output market conditions deteriorate, i.e., $I_{t} \geq 0$ for all $t$. It is well-known that irreversible investment models with non-geometric efficiency of capital goods generally do not allow for closed-form characterizations of the firm's optimal investment policy and equity value. ${ }^{9}$ Moreover, even in the geometric setting, irreversible investment models are less tractable in discrete time than in continuous time. The model we propose here, while stylized, can be solved in closed-form and generates predictions consistent with the economic intuition obtained in continuoustime, geometric efficiency models. Specifically, the user cost of capital in our model will be increasing in the probability of bad events, which is consistent with the Bernanke's bad news principle. Furthermore, the firm's optimal investment will be lumpy, in the sense that it will be optimal for the firm to refrain from investment for multiple consecutive periods.

To make our model analytically tractable, we assume that demand for the firm's output is governed by a regime-switching process. ${ }^{10}$ Formally, in each period the firm can either have monopoly (pricing) power or be a price-taker. If the firm has monopoly power in period

\footnotetext{
${ }^{9}$ For a more comprehensive discussion, see, for instance, Dixit and Pindyck $(1994,374)$. For general characterizations of the optimal investment policy in the absence of uncertainty (see, e.g., Arrow 1964; Benhabib and Rustichini 1991). In Rogerson (2008), investments are irreversible but the product market is assumed to be weakly expanding thus precluding the irreversibility constraint from binding. As a consequence, in that paper, investment irreversibility does not affect the user cost of capital: the Bernanke's (1983) bad news principle does not apply since there are never any bad news in the output market.

${ }^{10}$ For a model with regime-switching demand and reversible investment, see Abel and Eberly (2011).
} 
$t$, then demand for its output is given by the following constant-elasticity function:

$$
P\left(Z_{t}, K_{t}\right)=\left(\frac{K_{t}}{Z_{t}}\right)^{-(1-\alpha)}
$$

where $P\left(Z_{t}, K_{t}\right)$ is the price of the firm's output if the quantity supplied is $K_{t}, Z_{t}$ is a stochastic demand shift parameter, and $0<\alpha<1$ determines the price elasticity of demand. As in Rogerson (2008), we assume that capital is the only production factor and that the firm's production function exhibits constant returns to scale. Conditional on having monopoly power in period $t$, the firm's total revenue is given by:

$$
P\left(Z_{t}, K_{t}\right) K_{t}=Z_{t}^{1-\alpha} K_{t}^{\alpha}
$$

The stochastic demand shift parameter $Z_{t}$ determines the size of the firm's output market: a larger value of $Z_{t}$ means that the firm can supply more output at any given price. In our model, the demand shift parameter is affected by two types of shocks - permanent and transitory. The permanent component of $Z_{t}$, which we denote $Z_{t}^{o}$, evolves according to the following process:

$$
Z_{t}^{o}=\mu_{t} Z_{t-1}^{o}
$$

where $\mu_{t}$ are independently and identically distributed random variables drawn from some distribution with support in $(1, \infty)$ and a mean of $\bar{\mu}$, so that $Z_{t+1}^{o} \geq Z_{t}^{o}$. We therefore assume that the permanent component of demand for the firm's output is weakly increasing over time, i.e., there are no permanent bad news associated with the output market in which the firm has pricing power. ${ }^{11}$ Let $r$ be the firm's cost of capital and $\gamma \equiv 1 /(1+r)$ be the corresponding discount factor. To ensure that the firm's equity value is always finite, we

\footnotetext{
${ }^{11}$ In fact, a weaker condition is sufficient: the premium market should not contract at a rate faster than the minimum depreciation rate of the firm's capital goods:

$$
\mu_{\min } \geq \min _{\tau=2, \ldots, T} \frac{x_{\tau}}{x_{\tau-1}} .
$$

In the geometric depreciation case, the above condition simplifies to $\mu_{\min } \geq 1-\delta$.
} 
assume that $\bar{\mu}<1+r$.

The actual value of the demand shift parameter in period $t$ is equal to the product of its permanent component and a transitory shock, $\epsilon_{t}$ :

$$
Z_{t}=\epsilon_{t} Z_{t}^{o}
$$

where $\epsilon_{t}$ are distributed identically and independently of each other as well as of $\left\{\mu_{t}\right\}_{t=1}^{\infty}$. The only constraint that we impose on the support of $\epsilon_{t}$ is that $\epsilon_{t}>0$; for instance, we allow for transitory bad news in the firm's output market $-\epsilon_{t}$ can be less than one. ${ }^{12}$ For the sake of convenience, we adopt the normalization that $\mathbb{E}_{t-1}\left[\epsilon_{t}^{1-\alpha}\right]=1$. Figure 1 illustrates the time evolution of the demand shift parameter.

To allow for the possibility of permanent unfavorable events in the product market, we assume that, in each period, the firm can lose its pricing power with probability $\lambda_{\mathcal{C}}$. If the firm does lose its pricing power, it can still sell any quantity of output at a random unit price of $p_{t}$. This price is given by:

$$
p_{t}=\xi_{t} p
$$

where $\xi_{t}$ is a transitory shock to the competitive price, distributed identically and independently of all other variables, with support in $\mathbb{R}_{+}$and mean equal to one. The mean of the competitive price, $p$, is assumed to be lower than the firm's marginal cost of production (to be formally defined later). ${ }^{13}$ The firm may return back to the monopolistic regime with probability $\lambda_{\mathcal{M}}$. If $\lambda_{\mathcal{M}}=0$, then once the pricing power is lost, it is lost forever. Other values of $\lambda_{\mathcal{M}}$ describe temporary (yet not fully transitory) crises, in which the firm must incur economic losses over a random number of periods. Note, however, that since $p>0$ and there are no variable costs of production, it is optimal for the firm to operate even in

\footnotetext{
${ }^{12}$ However, such transitory bad news do not have any effect on the user cost of capital identified in Rogerson (2008). The user cost of capital in our model is different from that in Rogerson (2008) due to the possibility of permanent bad news discussed below.

${ }^{13}$ In our analysis below, it is the mean value of the competitive price, $p$, that plays a central role in determining the optimal investment policy. Hence, we will often refer to $p$ as simply the competitive price.
} 
the competitive regime.

An alternative explanation for our model is that the firm has access to two output markets - with a generic and premium products. Whenever possible, the firm follows a differentiation strategy and participates in the premium market, in which it has some pricing power. The permanent component of demand in that market is growing over time. Occasionally, however, the firm is shut out of the premium market and can only use its assets to make and sell the generic product. We assume that the firm is not the cost leader in the generic market: it acts as a price-taker and the prevailing price of the generic product is lower than the firm's long-run marginal cost of production. The market for the generic product is large enough to absorb any quantity of output that the firm can supply. Since the price of the generic product is below the firm's marginal cost, it is only optimal for the firm to resort to that market temporarily, in periods in which it cannot access the premium market.

In traditional models of dynamic investment in capital stock, revenues are usually given by some variant of the Cobb-Douglas production function as in equation (3) in all states of the world (see, e.g., Chapter 11 in Dixit and Pindyck 1994). Good states of the world correspond to increasing values of $Z_{t}$, whereas bad states of the world obtain when $Z_{t}$ declines. Note that in such models, the price elasticity of demand is constant (determined by $\alpha$ ) across all states of the world. In our model, the price elasticity of demand is the same in all good states, yet demand becomes perfectly elastic when the firm switches to the competitive regime. In practice, when demand for a firm's output declines, the firm is also likely to lose some but not all of its pricing power. Such situations will fall somewhere in between the traditional models, in which pricing power is unaffected by declining demand, and our model, in which declining demand always entails a complete loss of pricing power. We will show that goal congruence can be attained using essentially the same approach in both types of models. However, our model allows for a closed-form solution for the firm's optimal investment policy for arbitrary efficiency patterns, whereas in the traditional model, one needs to restrict attention to the case of geometric efficiency. 
The assumption of time varying pricing power is also anecdotally important in some industries. For instance, Apple Inc. enjoyed significant success with its early products such as the Macintosh line of computers. Yet beginning in early 1990s, Apple's monopoly power began to be significantly undercut by cheaper alternatives known, at the time, as "PC clones." Apple responded by introducing lower cost products, but its financial performance remained poor in the early through mid-1990s. After re-hiring Steve Jobs as its CEO in 1997, the company was able to regain its monopoly power with products such as the iMac and iPod. In another example, when in 1990s Charles Schwab's new competitors, such as TD Ameritrade and $\mathrm{E}^{*}$ Trade, challenged its market position, the firm was able to regain its competitive advantage by adopting the strategy of service excellence. Charles Schwab later again found itself engaged in a price war when the tech bubble burst in 2000. This price war led simultaneously to a significant loss of pricing power and an excess capacity problem (see Martinez-Jerez 2005). Finally, in some industries, such as Pharmaceuticals and BioTech, firms lose a large share of their pricing power when their patent rights expire. They can still use their existing capacity to make drugs but demand becomes more elastic. To summarize, the combination of declining demand and a loss of pricing power appears to be relatively common in practice. Moreover, in many cases, firms manage to regain their pricing power and return to growth after some period of time.

Since investments come online with a lag of one period, the firm has to plan its capacity stock one period ahead of time. Accordingly, it will be convenient to say that the firm is in the competitive regime (or state), $\mathcal{C}$, in period $t$ if it can sell its output only in the generic market in period $t+1$; conversely, the firm is said to be in the monopoly regime, $\mathcal{M}$, in period $t$ if it has pricing power in period $t+1$. Throughout the paper, when we use the terms "regime" or "state", we refer to the presence (or absence) of one-period-ahead pricing power. Let $\rho_{t} \in\{\mathcal{C}, \mathcal{M}\}$ denote the firm's state in period $t$. Then, the firm's operating cash 
flow in period $t+1$ can be written as:

$$
R\left(p_{t+1}, Z_{t+1}, K_{t+1}\right)= \begin{cases}Z_{t+1}^{1-\alpha} K_{t+1}^{\alpha}, & \text { if } \rho_{t}=\mathcal{M} \\ p_{t+1} K_{t+1}, & \text { if } \rho_{t}=\mathcal{C}\end{cases}
$$

We assume that just prior to making investment $I_{t}$, the manager observes the current state of demand (i.e., whether the firm has pricing power in period $t+1$ ) and, if state is $\mathcal{M}$, the permanent component of demand in period $t+1, Z_{t+1}^{o}$. Transitory shocks $\epsilon_{t+1}$ and $\xi_{t+1}$ represent unexpected news that arrive after the capacity level for period $t+1$ has been installed, and are observed only after revenues of period $t+1$ are realized.

\section{OPTIMAL INVESTMENT POLICY}

In this section, we show that the firm's optimal investment policy has the following characteristics: i) the firm does not invest if it is in the competitive regime, and ii) if the firm is in the monopoly regime, it invests so as to equate the expected marginal revenue of the next period to a certain constant quantity, $\tilde{c}$. We refer to $\tilde{c}$ as the user cost of capital. The notion of the user cost of capital was first introduced in Jorgenson (1963) for the case of geometric efficiency. Arrow (1964) extended this concept to capital goods with arbitrary efficiency profiles, albeit his expression for the user cost of capital relied on a infinite sequence of recursively defined functions. Rogerson (2008) provided a simple closed-form expression for the user cost of capital for arbitrary efficiency profiles under additional simplifying assumptions on the price of new capital goods. Importantly, all closed-form expressions for the user cost of capital in these papers relied on either the assumption of investment being reversible or the output market being weakly expanding over time, i.e., assumptions that make the irreversibility constraint always slack.

Formally, in a model without bad news, Rogerson (2008) shows that the optimal invest- 
ment is to keep constant the one-period ahead expectation of the marginal revenue:

$$
\mathbb{E}_{t}\left[R_{K}\left(p_{t+1}, Z_{t+1}, K_{t+1}^{*}\right)\right]=c,
$$

where $R_{K}(\cdot, \cdot, \cdot)$ denotes the derivative with respect to $K$, and $c>0$ denotes the user cost of capital. To find the value of $c$, consider the optimal investment $I_{t}^{*}$, which leads to the optimal capital stock $K_{t+1}^{*}$. Since $I_{t}^{*}$ is optimal, the marginal benefit of increasing this investment by one dollar, while holding the future investment plan unchanged, must be equal to one. Therefore, we have:

$$
\sum_{\tau=1}^{T} \mathbb{E}_{t}\left[\gamma^{\tau} R_{K}\left(p_{t+\tau}, Z_{t+\tau}, K_{t+\tau}^{*}\right) \frac{\partial K_{t+\tau}}{\partial I_{t}}\right]=\sum_{\tau=1}^{T} \gamma^{\tau} c x_{\tau}=1
$$

where the first equality follows from the fact that $\partial K_{t+\tau} / \partial I_{t}=x_{\tau}$. Therefore, the user cost of capital in Rogerson's (2008) model is given by:

$$
c \equiv \frac{1}{\sum_{\tau=1}^{T} \gamma^{\tau} x_{\tau}}
$$

It is well-known that for the case of geometric efficiency, $c=r+\delta$ (Jorgenson, 1963).

The key step for deriving the optimal investment policy in our model is to extend the notion of the user cost capital to a setting with a potentially binding irreversibility constraint. Once we allow for the possibility of bad news, the firm can no longer ensure that (4) is satisfied for all $t$. Specifically, if the firm is in the competitive state in period $t$, then

$$
\mathbb{E}_{t}\left[R_{K}\left(p_{t+1}, Z_{t+1}, K_{t+1}^{*}\right)\right]=p,
$$

regardless of $K_{t+1}$. To ensure that the competitive state is indeed unfavorable to the firm (i.e., reflects bad news), we assume that $p<c$, where $c$ is given by equation (6). However, still, on the optimal investment path, the present value of the benefits generated by increasing 
investment $I_{t}^{*}$ by one dollar, holding the future investment plan fixed, must be equal to one whenever $I_{t}^{*}>0$. Since the firm earns less than $c$, on the margin, when it does not have pricing power, and since an analogue of (5) must still hold when $I_{t}^{*}>0$, it follows that the firm's marginal revenue must, in expectation, be greater than $c$ in periods in which it has monopoly power.

In Proposition 1, we show that it is optimal for the firm to (i) not invest in the competitive regime, and (ii) choose its investment in the monopoly regime so as to ensure that

$$
\mathbb{E}_{t}\left[R_{K}\left(p_{t+1}, Z_{t+1}, K_{t+1}^{*}\right)\right]=\tilde{c},
$$

where $\tilde{c}$ is the generalized user cost of capital that will be calculated in Lemma 1. As per our discussion above, the main property of $\tilde{c}$ is that the expected marginal benefit of increasing $I_{t}^{*}$ by one dollar is equal to one if the firm is in the monopoly state in period $t$ :

$$
\sum_{\tau=1}^{T} \gamma^{\tau} \mathbb{E}_{t}\left[R_{K}\left(p_{t+\tau}, Z_{t+\tau}, K_{t+\tau}^{*}\right) x_{\tau} \mid \rho_{t}=\mathcal{M}\right]=1
$$

Furthermore, the left-hand side of the equation above must be less than one if the firm is in the competitive state in period $t$.

To calculate $\tilde{c}$, let $\phi_{\tau}\left(\rho, \rho^{\prime}\right)$ be the probability that the firm is in regime $\rho^{\prime} \in\{\mathcal{C}, \mathcal{M}\}$ in $\tau$ periods from now if it starts in regime $\rho \in\{\mathcal{C}, \mathcal{M}\}$ today. For example, in this notation, we have: $\phi_{1}(\mathcal{M}, \mathcal{M})=1-\lambda_{\mathcal{C}}, \phi_{1}(\mathcal{M}, \mathcal{C})=\lambda_{\mathcal{C}}, \phi_{2}(\mathcal{M}, \mathcal{M})=\left(1-\lambda_{\mathcal{C}}\right)^{2}+\lambda_{\mathcal{C}} \lambda_{\mathcal{M}} \cdot{ }^{14}$ Note that

$$
\phi_{\tau}(\rho, \mathcal{M})+\phi_{\tau}(\rho, \mathcal{C})=1
$$

Now suppose the firm is in the monopoly regime in period $t$ and consider the marginal unit of investment on the optimal path. ${ }^{15}$ The benefit generated by this unit in period $t+1$

\footnotetext{
${ }^{14}$ It will be convenient to let $\phi_{0}(\rho, \rho) \equiv 1$ and $\phi_{0}\left(\rho, \rho^{\prime}\right) \equiv 0$ for $\rho \neq \rho^{\prime}$.

${ }^{15}$ The optimality of the investment policy discussed here is formally established in the proof of Proposition 1. At this stage, the goal of our discussion is simply to provide an intuitive justification for the definition of $\tilde{c}$ in equations (11-12).
} 
is equal to $x_{1} \tilde{c}$ since the firm will surely have monopoly power in that period. The marginal benefit of this investment in period $t+\tau$ depends on whether the firm is in the competitive or monopoly regime in period $t+\tau-1$ (see equations 8 and 7 ). The expected value of that benefit is given by

$$
\mathbb{E}_{t}\left[R_{K}\left(p_{t+\tau}, Z_{t+\tau}, K_{t+\tau}^{*}\right) \cdot \frac{\partial K_{t+\tau}}{\partial I_{t}} \mid \rho_{t}=\mathcal{M}\right]=\left(\phi_{\tau-1}(\mathcal{M}, \mathcal{M}) \tilde{c}+\phi_{\tau-1}(\mathcal{M}, \mathcal{C}) p\right) \cdot x_{\tau}
$$

Let $M R_{\tau}$ denote the expectation of the marginal return to capital in period $t+\tau$ under the optimal policy conditional on $\rho_{t}=\mathcal{M}$ :

$$
M R_{\tau} \equiv \mathbb{E}_{t}\left[R_{K}\left(p_{t+\tau}, Z_{t+\tau}, K_{t+\tau}^{*}\right) \mid \rho_{t}=\mathcal{M}\right]=\phi_{\tau-1}(\mathcal{M}, \mathcal{M}) \tilde{c}+\phi_{\tau-1}(\mathcal{M}, \mathcal{C}) p
$$

Then, (9) becomes:

$$
1=\sum_{\tau=1}^{T} \gamma^{\tau} \cdot M R_{\tau} \cdot x_{\tau}
$$

The equation above is linear in $\tilde{c}$, and thus it uniquely defines the user cost of capital. Lemma 1, proved in Appendix, characterizes the behavior of $\tilde{c}$ in model parameters.

Lemma 1 The user cost of capital $\tilde{c}$ that solves (12) has the following properties:

1. $\tilde{c}$ is always greater than or equal to $c$, with a strict equality achieved only if one of the following conditions hold: $p=c, \lambda_{\mathcal{C}}=0$, or $T=1$.

2. $\tilde{c}$ is monotonically decreasing in p, increasing in $\lambda_{\mathcal{C}}$, and decreasing in $\lambda_{\mathcal{M}}$.

The exact expression for the user cost of capital in Lemma 1 is provided in the Appendix. It takes a particularly compact form for assets with geometric efficiency:

$$
\tilde{c}=c+\frac{(c-p)(1-\delta) \lambda_{\mathcal{C}}}{c+(1-\delta) \lambda_{\mathcal{M}}}
$$


where $c \equiv r+\delta$ is the Jorgenson's (1963) user cost of capital, which does not take into account the possibly binding irreversibility constraint. Another straightforward special case obtains when $\lambda_{\mathcal{M}}=0, p=0$ and $\lambda_{\mathcal{C}}>0$, i.e., when the competitive state is permanent and the value of the firm's output and assets in that state is zero. Then,

$$
\tilde{c}=\frac{1}{\sum_{\tau=1}^{T} \gamma^{\tau}\left(1-\lambda_{\mathcal{C}}\right)^{\tau-1} x_{\tau}}
$$

In this case, the probability of bad events effectively serves as a hazard rate by reducing the periodic discount factor for periods $t+2$ and onwards from $\gamma$ to $\gamma\left(1-\lambda_{\mathcal{C}}\right)$.

Note that the three parameters that affect $\tilde{c}$ in Lemma $1-p, \lambda_{\mathcal{C}}$, and $\lambda_{\mathcal{M}}$ - regulate the severity $(p)$ and the probability of bad news $\left(\lambda_{\mathcal{C}}\right.$ and $\left.\lambda_{\mathcal{M}}\right)$. In contrast, the relative goodness of the good news (as measured by $\mu_{t}$ or $\bar{\mu}$ ) does not affect the user cost of capital. Therefore, our model exhibits the Bernanke's (1983) bad news principle: the marginal cost of capital only depends on how frequent and unfavorable the potential bad news are. ${ }^{16}$ To see the intuition behind this bad news principle, note that on the optimal investment path, the firm must be just indifferent between investing an additional dollar in capital stock or postponing this investment. The possibility and magnitude of future good news do not affect the rank ordering of these two alternatives. If a good news arrives in the future, both alternatives become more profitable: even if the firm did not invest in the last period, it can catch up by investing more subsequently. By way of contrast, the magnitude and severity of bad news can make investing look, in retrospect, less appealing than postponing investment. Once an investment has been made, the cost is sunk due to the irreversibility constraint, and if bad news arrive, the firm is committed to a negative NPV project. The anticipated future cost of the binding irreversibility constraint must be taken into account at each investment date, even when the firm is in the monopoly regime.

Proposition 1 shows that the firm's optimal investment policy is to invest only in the

\footnotetext{
${ }^{16}$ For an additional discussion of the bad news principle, see, for instance, Abel, Dixit, Eberly, and Pindyck (1996) and Dixit and Pindyck (1994, 40-41).
} 
monopoly regime solving:

$$
\max _{K_{t+1}}\left\{\mathbb{E}_{t}[\underbrace{R\left(p_{t+1}, Z_{t+1}, K_{t+1}\right)-\tilde{c} K_{t+1}}_{\pi_{t+1}}]\right\}
$$

Let $K_{t+1}^{*}$ denote the optimal capital stock for period $t+1, \pi_{t+1}$ denote the target function under the expectation operator in the optimization program above, and $\pi_{t+1}^{*}$ be the value of $\pi_{t+1}$ given the optimal capital choice, $K_{t+1}^{*}$. We will refer to $\pi_{t+1}$ as the firm's economic profit in period $t+1$. Since in the monopoly state, the revenue function is given by equation (3) and $\mathbb{E}_{t}\left[\epsilon_{t+1}^{1-\alpha}\right]=1$, we can write:

$$
\mathbb{E}_{t}\left[R\left(p_{t+1}, Z_{t+1}, K_{t+1}\right)\right]=\left(Z_{t+1}^{o}\right)^{1-\alpha} K_{t+1}^{\alpha}
$$

Substituting the expression above into the objective function in (13), taking the first-order condition with respect to $K_{t+1}$, and solving for $K_{t+1}^{*}$ yields:

$$
K_{t+1}^{*}=M^{\frac{1}{\alpha}} \cdot Z_{t+1}^{o}
$$

where $M \equiv(\alpha / \tilde{c})^{\frac{\alpha}{1-\alpha}}$. Substituting the expression above back into the target function in (13), we obtain that the expected value of optimized economic profits is also proportional to $Z_{t+1}^{o}$ and given by:

$$
\mathbb{E}_{t}\left[\pi_{t+1}^{*}\right]=(1-\alpha) M \cdot Z_{t+1}^{o}
$$

Proposition 1 It is optimal not to invest in the competitive regime. If the firm is in the monopoly regime in period $t$, the optimal investment policy solves:

$$
\max _{K_{t+1}}\left\{\mathbb{E}_{t}\left[R\left(p_{t+1}, Z_{t+1}, K_{t+1}\right)\right]-\tilde{c} K_{t+1}\right\}
$$

The optimal value of $K_{t+1}$ solving the problem above is given by: $K_{t+1}^{*}=M^{\frac{1}{\alpha}} Z_{t+1}^{o}$, where 
$M \equiv(\alpha / \tilde{c})^{\frac{\alpha}{1-\alpha}}$

Note that since the permanent component of demand in the premium market is always expanding and assets are weakly depreciating, the optimal investment $I_{t}^{*}$ leading to the capital stock level $K_{t+1}^{*}$ specified in equation (14) is non-negative as long as the firm does not start with excess capacity in period $t$. Therefore, once the firm is on the optimal capital stock path, it can always remain on it by making non-negative investments, and thus the policy described above is consistent with the irreversibility constraint.

\section{GOAL CONGRUENT PERFORMANCE MEASURES}

We now turn to characterizing the combinations of performance measures and accounting rules that can be used to incentivize a better informed manager to make optimal investments. Given the optimal investment policy described in the previous section, the principal needs to achieve two goals: (i) prevent the manager from investing in the competitive regime, and (ii) ensure that in the monopoly regime, the manager invests by myopically optimizing the expected value of the next period's economic profit calculated relative to user cost $\tilde{c}$.

We initially assume that the principal does not observe the current realizations of variables governing demand for the firm's output, i.e., the current state at date $t(\mathcal{M}$ or $\mathcal{C})$ and the value of $Z_{t+1}^{o}$. Recall that the manager is also not perfectly informed about next period's demand: in period $t$, the manager observes the permanent component of demand in period $t+1, Z_{t+1}^{o}$, but not the corresponding transitory shock, $\epsilon_{t+1}$. As a consequence, the principal cannot offer a forcing contract that would compensate the manager only if the choice of $I_{t}$ is revealed to be ex-post optimal once cash flows of period $t+1$ are realized. In fact, even after observing the realized cash flows, the principal cannot infer the exact value of the permanent component of the demand shift parameter at any point in time - this information is obscured by the presence of transitory demand shocks.

The principal offers the manager an employment contract that stipulates that the man- 
ager's compensation in each period will be proportional to performance measure $m_{t} .{ }^{17}$ The manager chooses investments so as to maximize the following expected utility function:

$$
U_{t}=\mathbb{E}_{t}\left[\sum_{s=t}^{n} \beta_{s} m_{s}\right] \text {, }
$$

where period $n$ denotes the manager's finite horizon, and $\beta_{s}$ are positive constants for all $s$. Parameters $\beta_{s}$ reflect the product of the percentage of the performance measure that is paid out to the manager and the manager's personal discount factor for period $s$. To simplify our analysis, we assume that when the contract is first signed, the firm is either already on the optimal investment path or has a capital stock that is below the optimal level.

As is usual in the goal congruence literature, the principal does not know anything about the agent's utility function other than that it is increasing in each $m_{s}$. For instance, our model can accommodate situations in which the manager is discounting payoffs at a privately known rate higher than that of the principal. Our analysis applies to contracts with fixed duration to which the manager can commit, in which case $n$ can be interpreted as the ending period of the contract. The contract can also be open-ended, and the manager can privately know that she would be leaving the firm by period $n$. Parameters $\beta_{s}$ can then reflect the manager's assessment of the probability that she would leave the firm by period $s$ for some exogenous reasons. One important possibility that is not covered by the utility function in (16) is that the manager's decision to quit may be correlated with the state of demand in the firm's output market. For instance, the manager may anticipate a higher probability of quitting after an onset of the competitive regime. Modeling such situations would require allowing for $\beta_{s}$ to be random variables correlated with past and contemporaneous values of $m_{t}$ as well as specifying the manager's outside options in each state of the world. Therefore,

\footnotetext{
${ }^{17}$ We describe the set of the possible performance measures below. While we do not explicitly motivate the use of periodic performance measurement in the manager's contract, we note that such compensation structure is common in practice and can be shown to be optimal in the presence of an agency problem as in Reichelstein (2000). In the model of that paper, the manager, who is responsible of investment decisions, can also exert unobservable effort that directly affects the current period cash flow. Reichelstein (2000) shows that periodic performance measurement can achieve goal congruence for investment decisions as well as motivate the optimal effort levels.
} 
we leave such situations outside the scope of this paper.

The goal of the principal is to incentivize the manager to make first-best investments given the information that the manager observes at each date. ${ }^{18}$ We will refer to performance measurement systems with this property as goal congruent since they align interests of the manager with those of the principal. All performance measures that we will consider are linear in accounting variables that are observed at date $t$, such as revenues, the aggregate depreciation expense, $D_{t}$, and the aggregate beginning-of-period book value of assets, $B V_{t-1}$. The book value of assets at date $t-1$ is assumed to be a linear combination of investments that survive to that date:

$$
B V_{t-1}=b v_{0} I_{t-1}+b v_{1} I_{t-2}+\ldots+b v_{T-1} I_{t-T}
$$

where $b v_{\tau} \geq b v_{s} \geq 0$ for $\tau \leq s$. Then, the aggregate depreciation expense of period $t$ can be written as:

$$
D_{t}=\left(b v_{0}-b v_{1}\right) I_{t-1}+\left(b v_{1}-b v_{2}\right) I_{t-2}+\ldots+b v_{T-1} I_{t-T}
$$

where the last term obtains because $b v_{T}=0$.

We now turn to describing our main goal congruent performance measurement system. A key element of this system is a depreciation rule that we label relative anticipated marginal benefit (RAMB) depreciation. To construct this rule, consider a positive investment made at date $t$. The principal initially gives the manager the "benefit of the doubt" and assumes that all investments are indeed made only in the monopoly regime. Then, recall that if this and all future investments are made optimally, the sequence of the marginal expected revenues with respect to $I_{t}$ over the next $T$ periods can be calculated using expression (10) above:

$$
\underbrace{M R_{1} \cdot x_{1}}_{\text {Period } 1 \text { of useful life }}, \underbrace{M R_{2} \cdot x_{2}}_{\text {Period } 2}, \cdots, \underbrace{M R_{T} \cdot x_{T}}_{\text {Period } T}
$$

\footnotetext{
${ }^{18}$ Again, as usual in the goal congruence literature, we ignore agency costs. For a model applying the goal congruence framework in a setting with an explicit moral hazard problem (see Reichelstein 2000). Dutta (2007) provides a survey of the goal congruence literature.
} 
Under the RAMB depreciation rule, the book value of one unit of the capital good of age $\tau$ is set equal to the present value of its remaining marginal expected benefits, as calculated from the vantage point of the asset acquisition date: ${ }^{19}$

$$
b v_{\tau}^{r a m b}=\sum_{i=1}^{T-\tau} \gamma^{i} \cdot M R_{\tau+i} \cdot x_{\tau+i} .
$$

By condition (12), $b v_{0}^{r a m b}=1$, and therefore in the period of capital good acquisition, its cost is fully capitalized on the balance sheet. After the acquisition date, the capital good is depreciated according to the fixed schedule in (18). As time goes by, regimes change, and so do the expectations of marginal benefits of investment $I_{t}$. However, the principal does not observe these regime changes and sticks to the fixed depreciation schedule adapted at the time of acquisition.

An alternative intuition for the capital good valuation rule in (18) can be gained if one considers a hypothetical competitive leasing market for capital goods. Consider a perfectly competitive manufacturer of capital goods who leases out their productive capacity to the producer of the final product. If the lessee does not have pricing power in period $t$, then the capital goods manufacturer will rent out its goods at price $p_{t}$ per unit of capacity. This is because the lessee will not pay a higher price if the price of its own output is $p_{t}$. In periods in which the lessee has pricing power, the manufacturer will charge a price of $\tilde{c}$ per unit of capacity. At these prices, the manufacturer will exactly break even if it constructs capital goods in periods in which the lessee is in the monopoly regime; no capital goods will be constructed when the lessee is in the competitive state. Each $b v_{\tau}^{\text {ramb }}$ represents the expected value of a unit of a capital good of age $\tau$ in this competitive rental market, where the expectation is taken conditionally on the lessee being in the monopoly state at the time of asset acquisition.

It remains to specify a performance measure that the principal can use in conjunction

\footnotetext{
${ }^{19}$ Here and below, the superscript ' $r a m b$ ' indicates that the quantity in question is calculated under the RAMB rule.
} 
with the RAMB depreciation to incentivize the optimal investment decisions by the manager. To this end, assume that the firm is in the monopoly state in period $t$. Recall that under the principal's desired investment rule, the following condition must hold in all future periods $t+\tau$ (see eq. 11):

$$
\mathbb{E}_{t}\left[R_{K}\left(p_{t+\tau}, Z_{t+\tau}, K_{t+\tau}^{*}\right) \mid \rho_{t}=\mathcal{M}\right]-M R_{\tau}=0
$$

The performance measure that we present below has the property that its expected marginal value in period $t+\tau$ is equal to

$$
\mathbb{E}_{t}\left[R_{K}\left(p_{t+\tau}, Z_{t+\tau}, K_{t+\tau}^{* *}\right) \cdot x_{\tau} \mid \rho_{t}=\mathcal{M}\right]-M R_{\tau} \cdot x_{\tau}
$$

for any path of capacity levels $K_{t+\tau}^{* *}$. Then, it is intuitive that if the manager implements the optimal investment path in all periods, the performance measure will be maximized in expectation on a period-by-period basis.

Specifically, consider the standard residual income measure defined as:

$$
m_{t}=R I_{t} \equiv \underbrace{R\left(p_{t}, Z_{t}, K_{t}\right)-D_{t}}_{\text {Net Income }}-r \cdot B V_{t-1}
$$

Assume the manager contemplates the choice of investment level in period $t$ when the firm is in the monopoly state. This investment will affect the values of the performance measure in the next $T$ periods. What is the effect of $I_{t}$ on $R I_{t+\tau}$ for $1 \leq \tau \leq T$ ? Ignoring the terms related only to past investments (which are sunk), the expected marginal effect $I_{t}$ on $R I_{t+\tau}$ can be written as:

$$
\underbrace{\mathbb{E}_{t}\left[R_{K}\left(p_{t+\tau}, Z_{t+\tau}, \hat{K}_{t+\tau}^{* *}\right) \cdot x_{\tau} \mid \rho_{t}=\mathcal{M}\right]}_{\text {Marginal effect on revenue }}-\underbrace{\left(b v_{\tau-1}^{r a m b}-b v_{\tau}^{r a m b}\right)}_{\text {Marginal effect on } D_{t+\tau}}-\underbrace{r \cdot b v_{\tau-1}^{r a m b}}_{\text {Marginal effect on } r B V_{t+\tau-1}}
$$

where $K_{t+\tau}^{* *}$ denotes the level of capital stock in period $t+\tau$ under the investment policy 
chosen by the manager. Note that for the RAMB depreciation rule given in (18), the sum of the last two terms in the expression above can be written as:

$$
(1+r) b v_{\tau-1}^{r a m b}-b v_{\tau}^{r a m b}=M R_{\tau} \cdot x_{\tau}
$$

Therefore, the total expected marginal impact of $I_{t}$ on $m_{t+\tau}$ is indeed given by expression (19).

The formal result in Proposition 2 relies on the additional assumption, which we will impose throughout the rest of the paper, that

$$
\lambda_{\mathcal{C}}+\lambda_{\mathcal{M}}<1
$$

This additional assumption ensures that state persistence is more likely than change. For example, under (21), the probability of the firm being in the competitive regime $\tau$ periods from now is higher conditional on the current state being competitive than monopolistic:

$$
\phi_{\tau}(\mathcal{C}, \mathcal{C})>\phi_{\tau}(\mathcal{M}, \mathcal{C})
$$

Conversely, this assumption also implies that

$$
\phi_{\tau}(\mathcal{M}, \mathcal{M})>\phi_{\tau}(\mathcal{C}, \mathcal{M})
$$

To illustrate the importance of assumption (21), consider a situation in which both $\lambda_{\mathcal{C}}$ and $\lambda_{\mathcal{M}}$ are close to one. In this case, the competitive and monopoly regimes alternate over time, and bad news of period $t$ correspond to good news of period $t+1$ and vice versa. Now assume that: (i) the firm is in the competitive regime in period $t$, (ii) the manager intends to stay with the firm until the end of period $t+2$, and (iii) the manager cares very little about the payoff in period $t+1\left(\beta_{t+1} \rightarrow 0\right)$ yet attaches a positive weight to compensation 
in period $t+2\left(\beta_{t+2}=1\right)$. Under these conditions, the manager may find it optimal to invest in period $t$, even though the firm is in the competitive state. This is because the manager is almost certain that the firm will have pricing power in period $t+2$ : it does not have pricing power in period $t+1$, and when both $\lambda_{\mathcal{C}}$ and $\lambda_{\mathcal{M}}$ are close to one, regimes almost surely switch every period. Therefore, the firm will need extra productive capacity in period $t+2$. This capacity can be installed by the manager either in period $t$ or $t+1$. In the former case, the charge in the residual income measure of period $t+2$ per unit of new capacity will be given by

$$
M R_{2}=\underbrace{\phi_{1}(\mathcal{M}, \mathcal{M})}_{\approx 0} \tilde{c}+\underbrace{\phi_{1}(\mathcal{M}, \mathcal{C})}_{\approx 1} p \approx p .
$$

By way of contrast, if the manager installs the extra capacity in period $t+1$ (as is optimal from the owner's perspective), the impact on period- $t+2$ residual income per unit of new capacity will be given by $M R_{1}=\tilde{c}>p$. Therefore, the performance evaluation system we propose can fail to incentivize the manager to refrain from investment in the competitive state when $(21)$ is violated. ${ }^{20}$

Proposition 2 Residual income based on the relative anticipated marginal benefit rule achieves goal congruence.

To a certain degree, the RAMB rule described above is a natural extension of the replacement cost rule identified in Rogerson (2008). Under both rules, the book value of a capital good is set equal to the present value of the future marginal investment benefits, where such benefits are calculated under the assumption that the firm's optimal investment policy will be adhered to in the current and all future periods. The main difference is that in Rogerson's (2008) model, the marginal benefits of each investment are deterministic (equal to $c$ ), but in our model they are stochastic and determined by the future product market regimes. Our

\footnotetext{
${ }^{20}$ Note that the counterexample we discuss here relies on the manager valuing $m_{t+2}$ more than $m_{t+1}$. It can be verified that condition (21) is, in fact, not necessary if $\beta_{s}$ are monotonically decreasing.
} 
results in the previous section demonstrate that the marginal investment benefits in good states of nature depend on the probability and severeness of the bad states of nature. As a consequence, the RAMB rule in our model depends on demand parameters $p, \lambda_{\mathcal{M}}$, and $\lambda_{\mathcal{C}}$ that characterize the prevalence of and conditions in the bad (competitive) regime; in contrast, the replacement cost rule in Rogerson's (2008) model depends only on the physical productivity parameters $x_{\tau}$.

Our RAMB rule is different from Rogerson's (2008) rule in yet another important respect: there no longer exists a straightforward economic interpretation for the firm's residual income under the RAMB rule. It is well-known that under Rogerson's (2008) depreciation rule, the firm's residual income, $R I_{t}$, is equal to its economic profit, $\pi_{t}$, in every period. However, in our model, due to the potential presence of bad news, it will generally be the case that

$$
\mathbb{E}_{t}\left[R I_{t+1}^{r a m b}\right] \neq \mathbb{E}_{t}\left[\pi_{t+1}\right]
$$

when the performance measurement system described in Proposition 2 is used. This is because $D_{t}^{r a m b}+r B V_{t-1}^{r a m b}$ will generally not be proportional to the firm's contemporaneous capital stock, and one should not expect $D_{t}^{r a m b}+r B V_{t-1}^{r a m b}$ to be equal to $\tilde{c} K_{t}$ as in Rogerson's model.

The reason for this is that the book value of each vintage now reflects the present value of its expected future marginal benefits conditional on the firm being in the monopoly regime at the time of acquisition of that vintage. As a consequence, any two vintages of capital goods are valued conditionally on different information. It is only the latest investment vintage that is valued based on the information about the latest regime; the valuation of older vintages ignores all information that arrived after their acquisition. It is, however, true that the expectation of residual income sufficiently far in the future is equal to the expectation of the corresponding economic profit:

$$
\mathbb{E}_{t}\left[R I_{t+T+1}^{r a m b}\right]=\mathbb{E}_{t}\left[\pi_{t+T+1}^{*}\right]
$$


The equality above holds only under the optimal investment policy. This is because looking forward from date $t$, an investment in period $t+i$ for $i \leq T$ is positive only if and only if the firm is in the monopoly state in period $t+i$. The RAMB depreciation rule will value this investment vintage conditionally on exactly this event. The information that will arrive after period $t+i$ will make the valuation of this vintage stale, but the unconditional effect of this new information is equal to zero from the vantage point of date $t$ or, in fact, $t+i$.

Our possibility result in Proposition 2 stands in contrast to the impossibility result in Baldenius et al. (2016). Baldenius et al. extend the model of Rogerson (1997) by allowing the manager to choose the timing of a single, fixed-scale investment and show that goal congruence is not attainable with any performance measure linear in accounting variables. In our model, the manager is responsible for an arguably richer set of decisions - she can choose the timing as well as the size of multiple investments, - yet it turns out that there exists a goal congruent performance evaluation scheme. There are two main reasons for this difference in results. First, our parametric specification of the demand functions, with the assumed linearity in the bad states of the world, significantly simplifies the option pricing calculations embedded in the investment problem. Specifically, our specification leads to a constant user cost of capital under the optimal investment policy. We show in Section 5.2 that goal congruence is still attainable with an analogue of the performance measurement system described above in models with a more traditional specification of demand functions if one is willing to restrict attention to capital goods with geometric efficiency. However, it is intuitive that the time- and state-invariance of the user cost of capital does not hold more generally in models with non-geometric efficiency and alternative demand specifications.

Another main reason for this difference in results is that in our problem each decision variable, $I_{t}$, is continuous, but it is discrete in Baldenius et al. (2016). In both models, the optimal investment policy equates the current benefits of investing in a new project to the value of the option to delay this investment. When the investment decision is discrete, both benefits and the option value of the investment are strictly greater than zero at the 
investment threshold. Then, the ranking of these alternatives depends on the discount factor applied in calculating the option value. Differences in discounting between the principal and the agent then make goal congruence impossible. In our setting, with a continuous investment decision, the principal needs to provide optimal incentives on the margin. Under the optimal investment policy, each marginal project has a zero NPV regardless of whether it is implemented right now or delayed into the future. ${ }^{21}$ Differences in discounting between the principal and the agent then do not pose a problem as long as the NPV of each project is properly allocated to the performance measures of different periods over its useful life.

To further illustrate the performance measurement scheme characterized in Proposition 2, we consider the special case of capital goods with geometric efficiency. Recall that in the setting with no bad news, the user cost of capital for such assets is given by $c=r+\delta$, where $\delta$ is the rate of periodic decline in productive capacity. Furthermore, in the absence of bad news, there is a unique depreciation policy that facilitates goal congruent performance measurement. Under this policy, capital goods are capitalized at acquisition and depreciated at rate $\delta$, i.e., at their economic depreciation rate (see Rogerson 2008, Nezlobin et al. 2015):

$$
b v_{\tau}^{r c}=(1-\delta)^{\tau}
$$

However, the combination of residual income and geometric depreciation fails to achieve goal congruence once we allow for the possibility of bad news. ${ }^{22}$ Proposition 2 shows that efficient investment incentives can still be provided using residual income as the performance measure if the firm uses the RAMB rule instead. The following Corollary sheds more light on the structure of this rule for assets with geometric efficiency.

\footnotetext{
${ }^{21}$ Crucially for this claim, the NPV of the marginal project must be understood to be calculated under the assumption that the optimal investment policy will be followed in future periods. Holding the future investment plan fixed, the benefits of the marginal investment are then given by (17). By equation (12), the present value of these benefits is equal to one, i.e., the marginal investment cost.

${ }^{22}$ In fact, goal congruence cannot be achieved by any linear performance measure if assets are accounted for using geometric depreciation.
} 
Corollary 1 Assume that capital goods have geometric efficiency. Then,

$$
b v_{\tau}^{r a m b}=(1-\delta)^{\tau}\left(1-\frac{c-p}{c+(1-\delta) \lambda_{\mathcal{M}}} \phi_{\tau}(\mathcal{M}, \mathcal{C})\right)
$$

where $c=r+\delta$ and

$$
\phi_{\tau}(\mathcal{M}, \mathcal{C})=\frac{\lambda_{\mathcal{C}}\left(1-\left(1-\lambda_{\mathcal{C}}-\lambda_{\mathcal{M}}\right)^{\tau}\right)}{\lambda_{\mathcal{C}}+\lambda_{\mathcal{M}}}
$$

Furthermore, bv $v_{\tau}^{\text {ramb }}$ weakly increases in $p$ and $\lambda_{\mathcal{M}}$ and decreases in $\lambda_{\mathcal{C}}$ for all $\tau$.

One can immediately see that the RAMB rule is more conservative than the rule from Rogerson (2008), $b v_{\tau}^{r a m b} \leq(1-\delta)^{\tau}$. The equality is achieved only if $p=c$ (the "bad" news are just neutral) or if $\phi_{\tau}(\mathcal{M}, \mathcal{C})=0$ (the probability of transitioning into the competitive regime is zero). The RAMB depreciation rule does not belong to the geometric family: instead, it is a linear combination of two geometric schedules - one with a decline factor of $(1-\delta)$ and another one with a decline factor of $(1-\delta)\left(1-\lambda_{\mathcal{C}}-\lambda_{\mathcal{M}}\right)$. The rule becomes unequivocally less conservative as $p$ or $\lambda_{\mathcal{M}}$ increase and more conservative as $\lambda_{\mathcal{C}}$ increases.

Direct analytical expressions for the RAMB rule for general efficiency profiles are quite complex, but it is straightforward to check that an analogue of Corollary 1 holds for any efficiency profile with the useful life of capital goods is two periods.

Corollary 2 Assume that capital goods have a useful life of two periods. Then, the RAMB

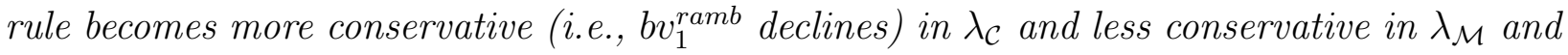
$p$.

To summarize, goal congruence in our model can be attained even if the principal is completely uninformed about the state of demand in the product market. The goal congruent performance measurement system that we described has the following characteristics. First, residual income is used as the performance measure, with the hurdle rate set equal to the firm's cost of capital. Second, the accounting valuation policy applied to each vintage of capital goods is based on the present value of the expected marginal benefits that this 
vintage is yet to generate, where the expectation is taken at time of acquisition of that vintage and conditional on the firm being in the monopoly regime at that date. The upshot of Corollaries 1 and 2 is that such asset valuation and depreciation policy is generally more conservative than the policy identified in Rogerson (2008), and the degree of its conservatism increases in the probability and severity of bad news.

\section{EXTENSIONS}

In this Section, we consider two extensions of our main model. First, we study a scenario with a partially informed principal, who observes the current state of demand $(\mathcal{C}$ or $\mathcal{M})$ but is uninformed about the size of the market in the good state $\left(Z_{t+1}^{o}\right)$. Under these assumptions, the principal can determine whether the optimal investment is zero or strictly positive, but whenever the optimal investment is positive, the principal does not have enough information to calculate its optimal size. Our goal here is to demonstrate that goal congruence can be achieved even with relatively straightforward accounting rules that depreciate capital goods in simple proportion to their productive capacity. To provide goal congruent incentives, it is sufficient to scale up the aggregate depreciation expense to reflect the potential future cost of the irreversibility constraint. Second, we consider a variant of our model with a more traditional specification of the output demand function, which is commonly considered in

the finance and economics literature. We show that all the results derived in the paper carry over to the setting with a Cobb-Douglas production function if one restricts attention to capital goods with geometric efficiency.

\section{Partially Informed Principal}

Assume that the principal observes the current market regime in each period. In this case, the performance measurement problem simplifies considerably since the principal can enforce zero investment when the competitive regime is observed. It remains to incentivize the manager to make optimal investments in the monopoly regime, i.e., to ensure that the 
manager chooses $K_{t+1}^{*}$ according to the following program:

$$
\max _{K_{t+1}}\left\{\mathbb{E}_{t}\left[R\left(Z_{t+1}, K_{t+1}\right)\right]-\tilde{c} \cdot K_{t+1}\right\} .
$$

We demonstrate that if the principal is partially informed, goal congruence be achieved even using perhaps the most straightforward depreciation policy, which we label the proportional rule. Under this rule, each unit of capital good is depreciated over time in simple proportion to the capacity it generates, so that:

$$
b v_{\tau}^{p} \equiv \frac{\sum_{i=\tau+1}^{T} x_{i}}{\sum_{i=1}^{T} x_{i}}
$$

for $1 \leq \tau \leq T .{ }^{23}$ For assets with constant efficiency over a finite useful life, $x_{1}=\ldots=x_{T}$, the proportional rule corresponds to straight-line depreciation.

Nezlobin et al. (2015) show that the proportional rule can be used to attain goal congruence in Rogerson's (2008) setting without unfavorable market events. The main observation behind this result is that the firm's aggregate depreciation expense in period $t+1$ can be written as:

$$
D_{t}^{p} \equiv \sum_{\tau=1}^{T}\left(b v_{\tau-1}^{p}-b v_{\tau}^{p}\right) I_{t-\tau}=\frac{\sum_{\tau=1}^{T} x_{\tau} I_{t-\tau}}{\sum_{i=1}^{T} x_{i}}=\frac{1}{\sum_{i=1}^{T} x_{i}} K_{t} .
$$

Now consider the following performance measure:

$$
R\left(Z_{t}, K_{t}\right)-\left(c \sum_{i=1}^{T} x_{i}\right) D_{t}^{p} .
$$

By construction, it follows that this performance measure is equal to the firm's economic profit (calculated relative to user cost $c$ ) in each period. Since, on the optimal investment path, the firm's expected economic profits are maximized on a period-by-period basis, the manager prefers the optimal investment path to any other regardless of the weights she attaches to the performance measures of different periods. Therefore, the performance measure

\footnotetext{
${ }^{23}$ This rule is also often referred to as the units of production method.
} 
in (24) achieves goal congruence in Rogerson's (2008) model.

To extend this result to our setting, the performance measure can be adjusted as follows:

$$
m_{t} \equiv R\left(Z_{t}, K_{t}\right)-\left(\tilde{c} \sum_{i=1}^{T} x_{i}\right) \cdot D_{t}^{p}
$$

The coefficient on the aggregate depreciation expense in our model is based on the new user cost of capital $\tilde{c}$ and thus exceeds that from Nezlobin et al. (2015). If the manager invests optimally in the monopoly regime, the value of the performance measure in (25) will be maximized in all periods in which the firm has pricing power. To complete the characterization of our goal congruent performance system, let the manager's performance measure be zero in all periods in which the firm does not have pricing power in the output market.

Observation 1 Assume the principal is partially informed, i.e., observes the current regime, $\mathcal{M}$ or $\mathcal{C}$, simultaneously with the manager. Then, goal congruence can be attained by the performance measurement system characterized by the following conditions:

- (i) The principal enforces zero investment in the competitive regime;

- (ii) In periods in which the firm does not have pricing power, $m_{t}$ is set equal to zero.

- (ii) Proportional depreciation is used together with the performance measure given in (25) in periods in which the firm has pricing power.

When the principal directly observes the states of the world in which zero investment is optimal, the only remaining incentive problem is to make the manager internalize a higher user cost of capital (relative to the setting without bad news) in the good states of the world. To this end, the principal can even rely on simple depreciation rules that do not reflect the nature of bad events. In this case, the managerial performance measure should reflect the expected future cost of the binding irreversibility constraints through properly calibrated 
coefficients on accounting variables. The measure in (25) achieves this goal by scaling up the total depreciation expense under the proportional rule by a factor that reflects the user cost of capital in the presence of bad news.

\section{Alternative Demand Specification}

Throughout the paper, we have assumed that demand follows a regime-switching process, and this assumption has been critical in allowing for a closed-form solution for the firm's optimal policy and its equity value. Does the main intuition from our analysis carry over to settings with more traditional demand specifications? In this section, we show that the performance measurement systems discussed earlier remain to be goal congruent in a scenario with positive or negative shocks to demand, even when such shocks do not correspond to our regime-switching setting. However, this extension of our model relies on the additional assumption that capital goods have geometric efficiency, which is common in the finance and economics literature. ${ }^{24}$

Assume that the firm's capital stock follows:

$$
K_{t+1}=(1-\delta) K_{t}+I_{I}
$$

i.e., capital goods have geometric efficiency with parameter $\delta$. Consider further the following process for the permanent component of the demand shift parameter:

$$
Z_{t}^{o}=\mu_{t} Z_{t-1}^{o}
$$

We no longer impose the regime-switching structure of demand; instead, we let $\mu_{t}$ vary from 0 to infinity. Specifically, let $\log \mu_{t}$ be distributed normally so that $\mathbb{E}\left[\mu_{t}\right]=\bar{\mu} \in \mathbb{R}^{+}$. The permanent component of the demand shift parameter thus follows a geometric Brownian

\footnotetext{
${ }^{24}$ It appears to be technically infeasible to extend our closed-form results to a setting with arbitrary efficiency patterns, irreversibility, and shocks to demand of the continuous nature described below. See, also, Dixit and Pindyck (1994, 374-377) for further details.
} 
motion in discrete time. To ensure that the firm's value is always finite, we assume that $\bar{\mu}<1+r$. The firm's revenue is given by:

$$
R\left(Z_{t}, K_{t}\right)=Z_{t}^{1-\alpha} K_{t}^{\alpha}
$$

where $Z_{t}=\epsilon_{t} Z_{t}^{o}$. Recall that in this specification, $\epsilon_{t}$ is the transitory shock to demand with $\mathbb{E}\left[\epsilon_{t}^{1-\alpha}\right]=1$. As before, the manager observes $\mu_{t}$ just prior to making investment $I_{t-1}$, but transitory shock $\epsilon_{t}$ is realized after $I_{t-1}$ is made. Note that $R(\cdot, \cdot)$ no longer depends on $p_{t}$ since in this demand formulation, there is no competitive regime.

Proposition 3 The firm's optimal investment policy is of a threshold type governed by some user cost $\tilde{c}$, i.e., if feasible, the firm chooses $I_{t}>0$ so that

$$
\mathbb{E}_{t}\left[R_{K}\left(Z_{t+1}, K_{t+1}^{*}\right)\right]=\tilde{c}
$$

If $I_{t}$ solving (27) is negative, the firm does not invest $\left(I_{t}=0\right)$.

Our discrete-time model does not allow for a closed-form expression for $\tilde{c}$. However, with the assumption of geometric efficiency and the revenue functions given by (26), the model considered in this section effectively becomes a discrete-time analogue of the traditional neoclassical model of irreversible investment under uncertainty widely studied in the finance and economics literature (see, e.g., Abel 1983; Chapter 11 in Dixit and Pindyck 1994; and Abel and Eberly 1996). Boyarchenko (2004) shows that in such continuous-time models, the bad news principle still applies in the sense that it is the downward uncertainty in the probability distribution of $\mu$ that affects the user cost of capital.

We now turn to the problem of providing a manager with goal congruent investment incentives. Consider some period in which $I_{t}>0$ is optimal. Note that by Proposition 3 
above, (if possible) $I_{t}$ will be chosen such that

$$
\mathbb{E}_{t}\left[R_{K}\left(Z_{t+1}, K_{t+1}^{*}\right)\right]=\tilde{c},
$$

which, after some algebra, is equivalent to

$$
K_{t+1}^{*}=Z_{t+1}^{o} / \omega^{*}
$$

where $\omega^{*} \equiv(\alpha / \tilde{c})^{-\frac{1}{1-\alpha}}$. Let

$$
\omega_{t} \equiv \frac{Z_{t+1}^{o}}{K_{t+1}}
$$

The firm's investment policy then can be understood as follows: if $\omega_{t}$ under zero investment in period $t$ is less than $\omega^{*}$, then the firm chooses $I_{t}>0$ so as to set $\omega_{t}=\omega^{*}$; otherwise, the firm does not invest. ${ }^{25}$ Under this policy, $\omega_{t}$ follows the process:

$$
\omega_{t+1}= \begin{cases}\frac{\mu_{t+2}}{(1-\delta)} \omega_{t}, & \text { if } \frac{\mu_{t+2}}{(1-\delta)} \omega_{t}<\omega^{*} \\ \omega^{*}, & \text { otherwise. }\end{cases}
$$

Using (26) and (28), we know that

$$
\mathbb{E}_{s-1}\left[R_{K}\left(Z_{s}, K_{s}\right)\right]=\alpha \underbrace{\mathbb{E}_{s-1}\left[\epsilon_{s}^{1-\alpha}\right]}_{=1}(\underbrace{Z_{s}^{o} / K_{s}}_{=\omega_{s-1}})^{1-\alpha}=\alpha \omega_{s-1}^{1-\alpha} .
$$

Therefore, if the firm invests in period $t$, then the following quantities are constants under the optimal investment policy:

$$
M R_{\tau} \equiv \mathbb{E}_{t}\left[R_{K}\left(Z_{t+\tau}, K_{t+\tau}\right) \mid \omega_{t}=\omega^{*}\right]=\alpha \mathbb{E}_{t}\left[\omega_{t+\tau-1}^{1-\alpha} \mid \omega_{t}=\omega^{*}\right]
$$

where the evolution of $\omega_{t}$ is given by (29). For convenience, let $M R_{1} \equiv \tilde{c}$. Using this notation,

\footnotetext{
${ }^{25}$ Recall that the manager observes $\mu_{t+1}$ prior to choosing $I_{t}$ and therefore can calculate $\omega_{t}$ for any choice of $K_{t+1}$.
} 
it must be that

$$
\sum_{\tau=1}^{\infty} \gamma^{\tau}(1-\delta)^{\tau-1} M R_{\tau}=1
$$

for else it would have been optimal for the firm to either increase or decrease investment $I_{t}$ relative to its optimal level. ${ }^{26}$

Analogously to (18), the relative anticipated marginal benefit rule can now be constructed as:

$$
b v_{\tau}^{r a m b}=\sum_{i=1}^{\infty} \gamma^{i}(1-\delta)^{\tau+i-1} M R_{\tau+i} .
$$

Condition (30) ensures that this policy satisfies the usual accounting clean surplus requirement, i.e., $b v_{0}^{r a m b}=1$. As in Section 4, if the manager is compensated based on residual income calculated using this accounting rule, then per unit of investment in period $t$, the manager's performance measure in period $t+\tau$ increases by

$$
(1-\delta)^{\tau-1}\left\{\mathbb{E}_{t}\left[R_{K}\left(Z_{t+\tau}, K_{t+\tau}\right)\right]-M R_{\tau}\right\}
$$

which is equal to zero if investment $I_{t}$ is chosen optimally in period $t$, is less than zero if the firm overinvests, and is greater than zero if the firm underinvests. Therefore, the manager is always incentivized to choose the optimal investment level.

Proposition 4 Assume that revenues are given by (26) in all periods and capital goods have geometric efficiency. Then, residual income based on the relative anticipated marginal benefit rule achieves goal congruence.

Finally, let us assume that in the model described above, the principal is partially in-

\footnotetext{
${ }^{26}$ The effect of changing investment $I_{t}$ by one dollar holding the future investment plan unchanged is given by:

$$
\sum_{\tau=1}^{\infty} \gamma^{\tau} \mathbb{E}_{t}\left[\frac{\partial R\left(Z_{t+\tau}, K_{t+\tau}\right)}{\partial I_{t}}\right]=\sum_{\tau=1}^{\infty} \gamma^{\tau} \mathbb{E}_{t}\left[\frac{\partial R\left(Z_{t+\tau}, K_{t+\tau}\right)}{\partial K_{t+\tau}} \frac{\partial K_{t+\tau}}{\partial I_{t}}\right]=\sum_{\tau=1}^{\infty} \gamma^{\tau} M R_{\tau}(1-\delta)^{\tau-1}
$$

In general, $M R_{\tau}<\tilde{c}$ because the firm always attempts to keep the next period's expected marginal product of capital at or below $\tilde{c}$.
} 
formed and observes the bad demand realizations simultaneously with the manager. We define the "bad states of nature" to be the ones in which the optimal investment is zero. This implies that the principal observes the event that

$$
Z_{t+1}^{o}<(1-\delta) K_{t} \omega^{*}
$$

but if $Z_{t+1}^{o}$ is greater than the threshold above, the principal does not observe its exact value. When the condition above holds, the principal knows that zero investment is optimal and can enforce such policy by fiat. Moreover, if event (32) is observed in period $t$, the principal knows that in period $t+1$ the firm has excess capacity. In that case, consistent with the approach in Observation 1, the principal can set the managerial performance measure to zero in period $t+1$. It then remains to ensure that whenever a strictly positive investment is optimal in period $t$, the performance measure in period $t+1$ can be set equal to:

$$
m_{t+1}=R\left(Z_{t+1}, K_{t+1}\right)-\tilde{c} K_{t+1}
$$

This will provide optimal incentives to the manager since by condition (27), the optimal investment policy maximizes the quantity above in all periods immediately following the ones with non-zero investment.

The equality in (33) can be achieved using the approach from Observation 1, i.e., by applying the proportional depreciation combined with a performance measure that scales up the total depreciation expense in the calculation of income. It is well-known that for the geometric efficiency case, the proportional rule is given by:

$$
b v_{\tau}^{p}=(1-\delta)^{\tau} .
$$


Then, the total depreciation expense in period $t+1$ takes the following form:

$$
D_{t+1}^{p}=\delta I_{t}+\delta(1-\delta) I_{t-1}+\ldots=\delta K_{t+1}
$$

It now remains to define the managerial performance measure in periods following investment as:

$$
m_{t+1} \equiv R\left(Z_{t+1}, K_{t+1}\right)-\frac{\tilde{c}}{\delta} D_{t+1}^{p}
$$

Just as in Observation 1, so defined performance measurement scheme achieves goal congruence with a partially informed principal.

\section{CONCLUSION}

In this paper, we have studied the problem of incentive provision for a better informed manager who makes sequential irreversible investments in capital goods with arbitrary efficiency profiles. In contrast to earlier studies in this area, we allowed for the possibility of bad news about the product market conditions. We have shown that goal congruence is attainable for irreversible investment, even when the Bernanke's (1983) bad news principle applies.

There are several natural avenues for extending our analysis. First, we assumed that the firm employs only a single type of capital goods in its production technology. The main model of the paper remains analytically tractable with multiple types of capital, if one assumes that capital goods of all types have geometric efficiency (albeit with different rates of economic depreciation), the aggregate production function is Leontieff, and the price in the competitive state is sufficiently low to ensure that it is always optimal for the firm to either invest in all types of capital goods or none at all. Obviously, these assumptions are somewhat restrictive. Studying the problem of performance measurement in richer settings with multiple types of capital goods is an interesting avenue for future research.

Second, there is perhaps more to be said about the full set of goal congruent performance measures in models like ours. The performance measurement system described in Proposition 
2 is not unique in providing goal congruent incentives in our model. If one restricts attention to linear performance measures, then all such performance measurement systems with fixed depreciation rules can be shown, using an approach similar to Nezlobin et al. (2015), to belong to a certain single-parameter family. This, however, still leaves open the question of existence of other systems, possibly non-linear or with stochastic depreciation policies, that can also achieve goal congruence.

Finally, our analysis in this paper has relied on several simplifying assumptions. For example, we assumed that the firm does not face capital adjustment costs or financing constraints. Studying the effects of such constraints on the managerial incentives to make irreversible capacity investments is another possible avenue for future research.

\section{REFERENCES}

Abel, A. 1983. Optimal investment under uncertainty. American Economic Review 73 (1): 228-233.

Abel, A., A. Dixit, J. Eberly, and R. Pindyck. 1996. Options, the value of capital, and investment. Quarterly Journal of Economics 111 (3): 753-777.

Abel, A., and J. Eberly. 1996. Optimal investment with costly reversibility. Review of Economic Studies 63 (4): 581-593.

Abel, A., and J. Eberly. 2011. How Q and cash flow affect investment without frictions: An analytic explanation. Review of Economic Studies 78: 1179-1200.

Arrow, K. 1964. Optimal capital policy, cost of capital and myopic decision rules. $A n$ nals of the Institute of Statistical Mathematics 1-2: 21-30. 
Arya, A., and J. Glover. 2001. Option value to waiting created by a control problem. Journal of Accounting Research 39: 405-415.

Baldenius, T., A. Nezlobin, and I. Vaysman. 2016. Managerial performance evaluation and real options. The Accounting Review 91 (3): 741-766.

Benhabib, J., and A. Rustichini. 1991. Vintage capital, investment, and growth. Journal of Economic Theory 55: 323-339.

Bernanke, B. 1983. Irreversibility, uncertainty, and cyclical investment. Quarterly Journal of Economics 98 (1): 85-106.

Boyarchenko, S. 2004. Irreversible decisions and record-setting news principles. American Economic Review 94 (3): 557-568.

Boyarchenko, S., and S. Levendorskii. 2007. Irreversible Decisions under Uncertainty: Optimal Stopping Made Easy. Springer.

Caskey, J., and J. Hughes. 2012. Assessing the impact of alternative fair value measures on the efficiency of project selection and continuation. The Accounting Review 87 (2): 483-512.

DeMarzo, P., and M. Fishman. 2007. Agency and optimal investment dynamics. The Review of Financial Studies 20 (1): 151-188.

Dixit, A., and R. Pindyck. 1994. Investment Under Uncertainty. Princeton, NJ: Princeton University Press. 
Dutta, S. 2007. Dynamic performance measurement. Foundations and Trends in Accounting $2(3): 175-240$.

Dutta, S., and S. Reichelstein. 2005. Accrual accounting for performance evaluation. Review of Accounting Studies 10: 527-552.

Dutta, S., and S. Reichelstein. 2010. Decentralized capacity management and internal pricing. Review of Accounting Studies 15 (3): 442-478.

Johnson, N., and T. Pfeiffer. 2016. Capital budgeting and divisional performance measurement. Foundations and Trends in Accounting 10 (1): 1-100.

Johnson, N., T. Pfeiffer, and G. Schneider. 2017. Two-stage capital budgeting, capital charge rates, and resource constraints. Review of Accounting Studies 22 (2): 933-963.

Johnson, N., T. Pfeiffer, and G. Schneider. 2013. Multistage capital budgeting for shared investments. Management Science 59 (5): 1213-1228.

Jorgenson, D. 1963. Capital theory and investment behavior. American Economic Review Papers and Proceedings 53: 247-259.

Livdan, D., and A. Nezlobin. 2017. Accounting rules, equity valuation, and growth options. Review of Accounting Studies 22 (3): 1122-1155.

Martinez-Jerez, F. A. 2005. Understanding customer profitability at Charles Schwab. Harvard Business School Case \#106-002. 
McNichols, M., M. Rajan, and S. Reichelstein. 2014. Conservatism correction for the marketto-book ratio and Tobin's Q. Review of Accounting Studies 19 (4): 1393-1435.

Nezlobin, A. 2012. Accrual accounting, informational sufficiency, and equity valuation. Journal of Accounting Research 50: 233-273.

Nezlobin, A., M. Rajan, M. and S. Reichelstein. 2012. Dynamics of rate of return regulation. Management Science 58: 980-995.

Nezlobin, A., M. Rajan, M. and S. Reichelstein. 2016. Structural properties of the price-toearnings and price-to-book ratios. Review of Accounting Studies 21 (2): 438-472.

Nezlobin, A., S. Reichelstein, and Y. Wang. 2015. Managerial performance evaluation for capacity investments. Review of Accounting Studies 20 (1): 283-318.

Pfeiffer, T., G. Schneider. 2007. Residual income based compensation schemes for controlling investment decisions under sequential private information. Management Science 53: 495-507.

Rajan, M., and S. Reichelstein. 2009. Depreciation rules and the relation between marginal and historical cost. Journal of Accounting Research 47: 823-867.

Reichelstein, S. 1997. Investment decisions and managerial performance evaluation. Review of Accounting Studies 2: 157-180.

Reichelstein, S. 2000. Providing managerial incentives: cash flows versus accrual accounting. Journal of Accounting Research 38 (2): 243-269. 
Reichelstein, S., and A. Rohlfing-Bastian. 2015. Levelized product cost: Concept and decision relevance. The Accounting Review 90 (4): 1653-1682.

Reichelstein, S., and A. Sahoo. 2018. Relating product prices to long-run marginal cost: Evidence from solar photovoltaic modules. Contemporary Accounting Research 35: 1464-1498.

Rogerson, W. 1997. Inter-temporal cost allocation and managerial investment incentives: A theory explaining the use of economic value added as a performance measure. Journal of Political Economy 105 (4): 770-795.

Rogerson, W. 2008. Intertemporal cost allocation and investment decisions. Journal of Political Economy 116: 931-950.

Rogerson, W. 2011. On the relationship between historic cost, forward looking cost, and long run marginal cost. Review of Network Economics 10 (2): 1-31.

Zhang, G. 2000. Accounting information, capital investment decisions, and equity valuation: Theory and implications. Journal of Accounting Research 38 (2): 271-295.

\section{APPENDIX}

\section{Proof of Lemma 1.}

Using equations (11) and (12), $\tilde{c}$ can be written as:

$$
\tilde{c}=p+\frac{c-p}{c \cdot \sum_{\tau=1}^{T} \gamma^{\tau} x_{\tau} \phi_{\tau-1}(\mathcal{M}, \mathcal{M})} .
$$

The equation above obtains using straightforward algebra by recalling that $c=\left(\sum_{\tau=1}^{T} \gamma^{\tau} x_{\tau}\right)^{-1}$ 
and $\phi_{\tau-1}(\mathcal{M}, \mathcal{C})=1-\phi_{\tau-1}(\mathcal{M}, \mathcal{M})$. Since each $\phi_{\tau-1}(\mathcal{M}, \mathcal{M}) \leq 1$, it is straightforward to see that $\tilde{c} \geq c$. Similarly, the derivative of $\tilde{c}$ with respect to $p$ is given by:

$$
1-\frac{1}{c \cdot \sum_{\tau=1}^{T} \gamma^{\tau} x_{\tau} \phi_{\tau-1}(\mathcal{M}, \mathcal{M})} \leq 0
$$

It remains to check the derivatives of $\tilde{c}$ with respect to $\lambda_{\mathcal{M}}$ and $\lambda_{\mathcal{C}}$. The two derivative are very similar, so we only present the proof for monotonicity in $\lambda_{\mathcal{C}}$. To simplify notation, let $\phi_{\tau-1} \equiv \phi_{\tau-1}(\mathcal{M}, \mathcal{M})$ and $\phi_{\tau-1}^{\prime} \equiv \partial \phi_{\tau-1}(\mathcal{M}, \mathcal{M}) / \partial \lambda_{\mathcal{C}}$. The derivative of $\tilde{c}$ in (34) with respect to $\lambda_{\mathcal{C}}$ is of the same sign as

$$
-\sum_{\tau=1}^{T} \gamma^{\tau} x_{\tau} \phi_{\tau-1}^{\prime}
$$

Note that

$$
\phi_{\tau}=\phi_{\tau-1}\left(1-\lambda_{\mathcal{C}}\right)+\left(1-\phi_{\tau-1}\right) \lambda_{\mathcal{M}}=\lambda_{\mathcal{M}}+\phi_{\tau-1}\left(1-\lambda_{\mathcal{C}}-\lambda_{\mathcal{M}}\right)
$$

From this, it follows that

$$
\phi_{\tau}^{\prime}=\phi_{\tau-1}^{\prime}\left(1-\lambda_{\mathcal{C}}-\lambda_{\mathcal{M}}\right)-\phi_{\tau-1}
$$

Recall that all $\phi_{\tau}$ are between zero and one and $\phi_{0}^{\prime}=0$. Then, if $1-\lambda_{\mathcal{C}}-\lambda_{\mathcal{M}} \geq 0$, all $\phi_{\tau}^{\prime} \leq 0$, and the expression in (35) is positive, which implies that $\tilde{c}$ is increasing in $\lambda_{\mathcal{C}}$.

Now assume that $1-\lambda_{\mathcal{C}}-\lambda_{\mathcal{M}}<0$ and consider some positive $\phi_{\tau}^{\prime}$. By $(37), \phi_{\tau-1}^{\prime}$ must be negative. ${ }^{27}$ Consider the sum of the two terms in (35) that include $\phi_{\tau}^{\prime}$ and $\phi_{\tau-1}^{\prime}$ :

$$
\gamma^{\tau} x_{\tau} \phi_{\tau-1}^{\prime}+\gamma^{\tau+1} x_{\tau+1} \phi_{\tau}^{\prime}=\underbrace{\phi_{\tau-1}^{\prime}}_{\leq 0} \underbrace{\left(\gamma^{\tau} x_{\tau}+\gamma^{\tau+1} x_{\tau+1}\left(1-\lambda_{\mathcal{C}}-\lambda_{\mathcal{M}}\right)\right)}_{\geq 0}-\underbrace{\gamma^{\tau+1} x_{\tau+1} \phi_{\tau}}_{\geq 0} \leq 0
$$

where the second underbraced term is non-negative because $x_{\tau}$ are declining, $\gamma<1$, and

\footnotetext{
${ }^{27}$ Note furthermore that $\phi_{0}^{\prime}=0$, therefore if $\phi_{\tau}^{\prime}$ is positive, $\tau>0$.
} 
$-1 \leq 1-\lambda_{\mathcal{C}}-\lambda_{\mathcal{M}}<0$. Therefore, even if a positive term appears in the sum in (35), it will be dominated by the negative term immediately preceding it.

\section{Proof of Proposition 1.}

The main steps of the proof are as follows. ${ }^{28}$ Consider constant $\tilde{c}$ defined in equations (11-12). We will study the following extended problem (EP). Assume that, in addition to all other transactions described in the model, the firm can enter one-period forward contracts for capacity services. If the firm is in regime $\mathcal{M}(\mathcal{C})$ in period $t$, it can commit to renting or renting out any amount of period $t+1$ capacity at price $\tilde{c}$ ( $p$ in regime $\mathcal{C}$ ) to be paid or received in period $t+1$. Note that the set of feasible actions for the firm in problem $E P$ is a superset of that in the original problem. Therefore, if there exists an investment policy that is optimal in problem $E P$ and never requires the firm to enter forward contracts described above, then this investment policy is, a fortiori, optimal for the firm's original investment problem. We will show that the investment policy described in the Proposition (hereafter, the candidate policy) is optimal for problem EP. Note that under this policy, the following condition holds for all $t$ :

$$
\mathbb{E}_{t}\left[R_{K}\left(p_{t+1}, Z_{t+1}, K_{t+1}^{*}\right)\right]= \begin{cases}\tilde{c}, & \text { if regime is } \mathcal{M} \text { in period } t \\ p, & \text { if regime is } \mathcal{C} \text { in period } t\end{cases}
$$

Let $I_{t}^{*}$ denote the firm's investment in period $t$ under the candidate policy.

Let $q_{t+1}$ be the quantity of the product that the firm supplies to the output market (it can be different from $K_{t+1}$ in problem EP because of capacity renting). For any optimal

\footnotetext{
${ }^{28}$ We thank an anonymous referee for suggesting this proof idea.
} 
policy in problem $E P$, it must be that:

$$
\mathbb{E}_{t}\left[\frac{\partial R\left(p_{t+1}, Z_{t+1}, q_{t+1}\right)}{\partial q_{t+1}}\right]= \begin{cases}\tilde{c}, & \text { if regime is } \mathcal{M} \text { in period } t \\ p, & \text { if regime is } \mathcal{C} \text { in period } t\end{cases}
$$

Otherwise, the firm could increase the value of its cash flows further by entering additional forward contracts in period $t$ to increase/decrease its period- $t+1$ capacity. Therefore, the optimal quantities in problem $E P$ are equal to $K_{t+1}^{*}$, and our candidate policy generates the optimal revenues from the product market. It remains to check that the candidate policy also acquires capacity in the most efficient way.

Consider some optimal investment/rental policy for problem EP and let $I_{t}^{E P}$ denote the corresponding investment levels. We will show that even though it is possible that $I_{t}^{E P}$ is different from $I_{t}^{*}$ for some $t$, the two policies still lead to the same present value of cash flows. Consider the first period in which $I_{t}^{E P} \neq I_{t}^{*}$, say $I_{t}^{E P}>I_{t}^{*}$. We can then modify our candidate policy by increasing the investment in period $t$ by $I_{t}^{E P}-I_{t}^{*}$ (so that it matches investment $\left.I_{t}^{E P}\right)$ and committing to enter forward contracts to rent out $x_{i}\left(I_{t}^{E P}-I_{t}^{*}\right)$ units of capacity for periods $t+i, 1 \leq i \leq T$.

The present value of these transactions depends on the current regime. If the firm is in regime $\mathcal{M}$ in period $t$, it is given by:

$$
\left(I_{t}^{E P}-I_{t}^{*}\right)\left(-1+\sum_{\tau=1}^{T} \gamma^{\tau}\left(\phi_{\tau-1}(\mathcal{M}, \mathcal{M}) \tilde{c}+\phi_{\tau-1}(\mathcal{M}, \mathcal{C}) p\right) x_{\tau}\right)=0
$$

by the definition of $\tilde{c}$ in (11-12). Analogously, if the firm is in regime $\mathcal{C}$, the present value of the same adjustments can be written as:

$$
\left(I_{t}^{E P}-I_{t}^{*}\right)\left(-1+\sum_{\tau=1}^{T} \gamma^{\tau}\left(\phi_{\tau-1}(\mathcal{C}, \mathcal{M}) \tilde{c}+\phi_{\tau-1}(\mathcal{C}, \mathcal{C}) p\right) x_{\tau}\right)
$$

It remains to show that the expression above is not greater than zero. To this end, we will 
show that the sum in (38) is not less than the one in (39).

Recalling that $\phi_{\tau-1}(\mathcal{M}, \mathcal{C})=1-\phi_{\tau-1}(\mathcal{M}, \mathcal{M}), \phi_{\tau-1}(\mathcal{C}, \mathcal{C})=1-\phi_{\tau-1}(\mathcal{C}, \mathcal{M})$, and $\tilde{c}>p$, it suffices to check that

$$
\sum_{\tau=1}^{T} \gamma^{\tau} x_{\tau} \phi_{\tau-1}(\mathcal{M}, \mathcal{M}) \geq \sum_{\tau=1}^{T} \gamma^{\tau} x_{\tau} \phi_{\tau-1}(\mathcal{C}, \mathcal{M})
$$

According to equation (36) in the proof of Lemma 1,

$$
\phi_{\tau}(\mathcal{M}, \mathcal{M})=\lambda_{\mathcal{M}}+\phi_{\tau-1}(\mathcal{M}, \mathcal{M})\left(1-\lambda_{\mathcal{C}}-\lambda_{\mathcal{M}}\right)
$$

We can similarly write that

$$
\phi_{\tau}(\mathcal{C}, \mathcal{M})=\lambda_{\mathcal{M}}+\phi_{\tau-1}(\mathcal{C}, \mathcal{M})\left(1-\lambda_{\mathcal{C}}-\lambda_{\mathcal{M}}\right)
$$

Note that $\phi_{0}(\mathcal{M}, \mathcal{M})>\phi_{0}(\mathcal{C}, \mathcal{M})$. It follows that if $1-\lambda_{\mathcal{C}}-\lambda_{\mathcal{M}}>0$, then

$$
\phi_{\tau}(\mathcal{M}, \mathcal{M})>\phi_{\tau}(\mathcal{C}, \mathcal{M}) \text { for all } \tau
$$

The inequality above will not, however, hold generally if $1-\lambda_{\mathcal{C}}-\lambda_{\mathcal{M}} \leq 0$. Yet equations (41-42) also imply that:

$$
\begin{gathered}
\phi_{\tau}(\mathcal{M}, \mathcal{M})=\lambda_{\mathcal{M}}\left(2-\lambda_{\mathcal{C}}-\lambda_{\mathcal{M}}\right)+\phi_{\tau-2}(\mathcal{M}, \mathcal{M})\left(1-\lambda_{\mathcal{C}}-\lambda_{\mathcal{M}}\right)^{2} \\
\phi_{\tau}(\mathcal{C}, \mathcal{M})=\lambda_{\mathcal{M}}\left(2-\lambda_{\mathcal{C}}-\lambda_{\mathcal{M}}\right)+\phi_{\tau-2}(\mathcal{C}, \mathcal{M})\left(1-\lambda_{\mathcal{C}}-\lambda_{\mathcal{M}}\right)^{2}
\end{gathered}
$$

The two equations above then imply that $\phi_{\tau}(\mathcal{M}, \mathcal{M})>\phi_{\tau}(\mathcal{C}, \mathcal{M})$ for all even $\tau$, regardless of the sign of $1-\lambda_{\mathcal{C}}-\lambda_{\mathcal{M}}$. 
To confirm (40), we need to check that

$$
\sum_{\tau=1}^{T} \gamma^{\tau} x_{\tau}\left(\phi_{\tau-1}(\mathcal{M}, \mathcal{M})-\phi_{\tau-1}(\mathcal{C}, \mathcal{M})\right) \geq 0
$$

Let us consider the sum of any two consecutive terms in (44) such that the first term of the pair is indexed by an odd $\tau$. Then, using (41-42), we obtain:

$$
\begin{array}{r}
\gamma^{\tau} x_{\tau}\left(\phi_{\tau-1}(\mathcal{M}, \mathcal{M})-\phi_{\tau-1}(\mathcal{C}, \mathcal{M})\right)+\gamma^{\tau+1} x_{\tau+1}\left(\phi_{\tau}(\mathcal{M}, \mathcal{M})-\phi_{\tau}(\mathcal{C}, \mathcal{M})\right)= \\
=\underbrace{\left(\phi_{\tau-1}(\mathcal{M}, \mathcal{M})-\phi_{\tau-1}(\mathcal{C}, \mathcal{M})\right)}_{\geq 0} \underbrace{\left(\gamma^{\tau} x_{\tau}+\gamma^{\tau+1} x_{\tau+1}\left(1-\lambda_{\mathcal{C}}-\lambda_{\mathcal{M}}\right)\right)}_{\geq 0},
\end{array}
$$

where the second term is positive because $\gamma<1, x_{\tau}$ are weakly decreasing, and $1-\lambda_{\mathcal{C}}-\lambda_{\mathcal{M}} \geq$ -1 . Therefore, if $T$ is even, inequality (44) obtains by breaking all terms into pairs of successive ones. If $T$ is odd, then the last term is greater than zero since $\phi_{T-1}(\mathcal{M}, \mathcal{M})>$ $\phi_{T-1}(\mathcal{C}, \mathcal{M})$, and the sum of the remaining terms is also weakly positive by applying $(45)$ to successive pairs.

\section{Proof of Proposition 2.}

Similar to the proof of Proposition 1, we will consider an extended problem where, if the firm is in the monopoly state in period $t$, the manager can either rent or rent out capacity in period $t+1$ at cost $\tilde{c}$ per unit of capacity per period of time. The decision how much capacity to rent (or rent out) has to be made one period ahead of time, i.e., in period t for period $t+1$. We will show that the optimal investment policy, without renting, is preferred by the manager to any other policy even in the extended problem.

In the remainder of our proof, the following observation will be useful:

$$
\frac{\partial \mathbb{E}_{t}\left[m_{s}\right]}{\partial I_{t}}=\left\{\mathbb{E}_{t}\left[R_{K}\left(p_{s}, Z_{s}, K_{s}\right)\right]-M R_{s-t}\right\} x_{s-t}
$$


for $t<s \leq t+T$. To prove (46), note that, given the residual income performance measure,

$$
\begin{aligned}
\frac{\partial \mathbb{E}_{t}\left[m_{s}\right]}{\partial I_{t}} & =\mathbb{E}_{t}\left[R_{K}\left(p_{s}, Z_{s}, K_{s}\right)\right] \frac{\partial K_{s}}{\partial I_{t}}-\frac{\partial\left(D_{s}^{r a m b}+r B V_{s-1}^{r a m b}\right)}{\partial I_{t}} \\
& =\mathbb{E}_{t}\left[R_{K}\left(p_{s}, Z_{s}, K_{s}\right)\right] x_{s-t}-\left(b v_{s-t-1}^{r a m b}-b v_{s-t}^{r a m b}+r \cdot b v_{s-t-1}^{r a m b}\right) .
\end{aligned}
$$

Equation (46) now follows by noting that the definition of the RAMB rule in (18) implies that

$$
(1+r) b v_{\tau-1}^{f r c}-b v_{\tau}^{f r c}=M R_{\tau} \cdot x_{\tau}
$$

for $1 \leq \tau \leq T$.

We will prove the following claim by backward induction over $t$ : (i) if the firm is in the monopoly state in any period $s$ for $t \leq s \leq n$, the manager chooses investments $I_{s}, \ldots, I_{n-1}$ and, if needed, rents out capacity in periods where the firm has pricing power so as to $\operatorname{maximize} \mathbb{E}_{s}\left[\pi_{s+1}\right]$ :

$$
\mathbb{E}_{s}\left[R_{K}\left(p_{s+1}, Z_{s+1}, K_{s+1}^{*}\right)\right]=\tilde{c}
$$

(ii) the manager prefers not to invest in the competitive regime. ${ }^{29}$

First, consider the last investment for which the manager is compensated, $I_{n-1}$, and suppose that the firm is in the monopoly state in period $n-1$. Under the residual income performance measure and the RAMB depreciation rule, the manager seeks to maximize:

$$
\max _{I_{n-1}} \mathbb{E}_{n-1}\left[R\left(p_{n}, Z_{n}, K_{n}\right)-D_{n}^{f r c}-r B V_{n-1}^{f r c}\right]
$$

Using (46), the first-order condition for the problem reduces to: ${ }^{30}$

$$
\mathbb{E}_{n-1}\left[R_{K}\left(p_{n}, Z_{n}, K_{n}^{*}\right)\right]=\tilde{c}
$$

The manager therefore has incentives to choose $K_{n}^{*}$ optimally. If the corresponding invest-

\footnotetext{
${ }^{29}$ Recall that the manager has a finite horizon denoted by $n$.

${ }^{30}$ Recall that $\phi_{0}(\mathcal{M}, \mathcal{M})=1$, and $\phi_{0}(\mathcal{M}, \mathcal{C})=0$.
} 
ment $I_{n-1}^{*}$ is negative, the manager will rent out capacity in period $t+1$ so that (48) will still hold.

Now suppose the manager is in the competitive regime in period $n-1$. Then, equation (46) implies that

$$
\frac{\partial \mathbb{E}_{n-1}\left[m_{n}\right]}{\partial I_{n-1}}=(p-\tilde{c}) x_{1}<0
$$

so the manager is incentivized not to invest. This concludes the induction base case.

Next consider the manager's investment problem in period $t$ assuming that in all future periods (up to the manager's horizon), the firm will implement the optimal investment policy. Assume the firm is in the monopoly state; we will show that the optimal investment maximizes the expected value of all future performance measures. Indeed, since all future investments will be chosen optimally, for any $s$,

$$
\mathbb{E}_{t}\left[R_{K}\left(p_{s}, Z_{s}, K_{s}^{*}\right)\right]=\phi_{s-t-1}(\mathcal{M}, \mathcal{M}) \tilde{c}+\phi_{s-t-1}(\mathcal{M}, \mathcal{C}) p
$$

Then, by equation (46):

$$
\frac{\partial \mathbb{E}_{t}\left[m_{s}\right]}{\partial I_{t}}=\left\{\mathbb{E}_{t}\left[R_{K}\left(p_{s}, Z_{s}, K_{s}^{*}\right)\right]-\left(\phi_{s-t-1}(\mathcal{M}, \mathcal{M}) \tilde{c}+\phi_{s-t-1}(\mathcal{M}, \mathcal{C}) p\right)\right\} x_{s-t}=0
$$

and the optimal level of investment maximizes each $\mathbb{E}_{t}\left[m_{s}\right]{ }^{31}$

We now show that if the firm is in the competitive regime in period $t$, then the manager's preferred level of investment is zero under the scheme that we consider. Again, zero investment maximizes the expected value of the managerial performance measure in all future

\footnotetext{
${ }^{31}$ If the firm has excess capacity in period $t$, the manager is incentivized to rent out so that $\mathbb{E}_{t}\left[R_{K}\left(p_{t+1}, Z_{t+1}, K_{t+1}^{*}\right)\right]=\tilde{c}$
} 
periods. In the competitive state,

$$
\begin{aligned}
\mathbb{E}_{t}\left[R_{K}\left(p_{s}, Z_{s}, K_{s}^{*}\right)\right] & =\phi_{s-t-1}(\mathcal{C}, \mathcal{M}) \tilde{c}+\phi_{s-t-1}(\mathcal{C}, \mathcal{C}) p \\
& <\phi_{s-t-1}(\mathcal{M}, \mathcal{M}) \tilde{c}+\phi_{s-t-1}(\mathcal{M}, \mathcal{C}) p
\end{aligned}
$$

The last inequality holds because $\tilde{c}>p$, and we have already established in the proof of Proposition 1 that $\phi_{s-t-1}(\mathcal{M}, \mathcal{M})>\phi_{s-t-1}(\mathcal{C}, \mathcal{M})$ if $1-\lambda_{\mathcal{M}}-\lambda_{\mathcal{C}}>0$; see equation (43). Equation (46) then implies that

$$
\frac{\partial \mathbb{E}_{t}\left[m_{s}\right]}{\partial I_{t}}<0
$$

for all $s>t$ and all positive levels of investment. Then, the manager is better off on a periodby-period basis under no investment. To conclude the proof, note that if the manager starts out without excess capacity at the initial hiring date, then the capacity levels given by equation (47) can be implemented without access to the rental market.

\section{Proof of Corollary 1.}

To prove equation (23), note that

$$
\phi_{\tau}(\mathcal{M}, \mathcal{C})=\lambda_{\mathcal{C}}+\left(1-\lambda_{\mathcal{M}}-\lambda_{\mathcal{C}}\right) \phi_{\tau-1}(\mathcal{M}, \mathcal{C})
$$

with the initial condition that $\phi_{0}(\mathcal{M}, \mathcal{C})=0$. Equation $(23)$ can then be established by induction over $\tau$ using the recursive formula above. Equation (22) then obtains from the definition of $b v_{\tau}^{\text {ramb }}$ in equation (18), applying (11), recalling that $\phi_{\tau-1}(\mathcal{M}, \mathcal{M})=1-\phi_{\tau-1}(\mathcal{M}, \mathcal{C})$, and adding up geometric progressions.

Next note that

$$
\frac{\partial b v_{\tau}^{r a m b}}{\partial p}=(1-\delta)^{\tau} \frac{\phi_{\tau}(\mathcal{M}, \mathcal{C})}{\left(c+(1-\delta) \lambda_{\mathcal{M}}\right)}>0
$$


It can then be verified that

$$
\frac{\partial b v_{\tau}^{r a m b}}{\partial \lambda_{\mathcal{C}}}=-\frac{(1-\delta)^{\tau}(c-p) \Pi}{\left(1-\lambda_{\mathcal{C}}-\lambda_{\mathcal{M}}\right)\left(\lambda_{\mathcal{C}}+\lambda_{\mathcal{M}}\right)^{2}\left(c+(1-\delta) \lambda_{\mathcal{M}}\right)}
$$

where

$$
\Pi \equiv \lambda_{\mathcal{M}}\left(\left(1-\lambda_{\mathcal{C}}-\lambda_{\mathcal{M}}\right)-\left(1-\lambda_{\mathcal{C}}-\lambda_{\mathcal{M}}\right)^{\tau}\right)+\left(1-\lambda_{\mathcal{C}}-\lambda_{\mathcal{M}}\right)^{\tau}\left(\lambda_{\mathcal{C}}+\lambda_{\mathcal{M}}\right)\left(\tau \lambda_{\mathcal{C}}+\lambda_{\mathcal{M}}\right)
$$

Constant $\Pi$ defined above is positive when $\lambda_{\mathcal{C}}+\lambda_{\mathcal{M}}<1$, and therefore $\frac{\partial b v_{\tau}^{\text {ramb }}}{\partial \lambda_{\mathcal{C}}}<0$. Using similar algebra, it is straightforward to verify that $\lambda_{\mathcal{C}}+\lambda_{\mathcal{M}}<1$ implies $\frac{\partial b v_{\tau}^{\text {ramb }}}{\partial \lambda_{\mathcal{M}}} \geq 0$.

\section{Proof of Corollary 2.}

Recall that $b v_{0}^{r a m b}=1$ and $b v_{2}^{r a m b}=1$, therefore it is only $b v_{\tau}^{1}$ that is affected by the parameters considered in the Corollary. Note further that

$$
b v_{\tau}^{1}=\gamma M R_{2}=\gamma^{-1}\left(\gamma M R_{1}+\gamma^{2} M R_{2}\right)-M R_{1}=1+r-\tilde{c}
$$

Therefore, the behavior of $b v_{\tau}^{1}$ in parameters is always the opposite of that of $\tilde{c}$, which together with Lemma 1 concludes the proof of the Corollary.

\section{Proof of Proposition 3.}

This result for $\delta=0$ (no economic depreciation) is proven in Boyarchenko and Levendorskii (2007), Chapter 9, pp. 161-165. ${ }^{32}$ In the model with no economic depreciation, the value function solves the following Bellman equation:

$$
V^{e x c f}\left(Z_{t}^{o}, K_{t}\right)=\sup _{I_{t}>0}\left\{\gamma \mathbb{E}\left[R\left(Z_{t+1}, K_{t}+I_{t}\right)+V^{e x c f}\left(Z_{t+1}^{o}, K_{t}+I_{t}\right)\right]-I_{t}\right\}
$$

where we have used that $K_{t+1}=K_{t}+I_{t}$, and $V^{\text {excf }}\left(Z_{t}^{o}, K_{t}\right)$ denotes the firm's value exoperating cash flow (after $R\left(Z_{t}, K_{t}\right)$ is paid out), but cum-investment. In contrast, when

\footnotetext{
${ }^{32}$ It is well known that this result holds in continuous time for general $\delta>0$ (see, e.g., Chapter 11 in Dixit and Pindyck 1994).
} 
$\delta>0$, the Bellman equation takes the following form:

$$
V^{e x c f}\left(Z_{t}^{o}, K_{t}\right)=\sup _{I_{t}>0}\left\{\gamma \mathbb{E}\left[R\left(Z_{t+1},(1-\delta) K_{t}+I_{t}\right)+V^{e x c f}\left(Z_{t+1}^{o},(1-\delta) K_{t}+I_{t}\right)\right]-I_{t}\right\}
$$

Note that all cash flows and, accordingly, the firm's value are homogeneous of degree one in $\left(Z_{t}^{o}, K_{t}\right)$. Therefore, equation (50) can be rewritten as:

$$
\begin{array}{r}
V^{e x c f}\left(Z_{t}^{o}, K_{t}\right)=\sup _{I_{t}>0}\left\{\gamma(1-\delta) \mathbb{E}\left[R\left(\frac{Z_{t+1}}{1-\delta}, K_{t}+\frac{I_{t}}{1-\delta}\right)+V^{e x c f}\left(\frac{Z_{t+1}^{o}}{1-\delta}, K_{t}+\frac{I_{t}}{1-\delta}\right)\right]\right. \\
\left.-(1-\delta) \frac{I_{t}}{1-\delta}\right\} .
\end{array}
$$

Letting $I_{t}^{\prime} \equiv \frac{I_{t}}{1-\delta}$ and comparing the equation above to (49), one can see that the problem with $\delta>0$ reduces to the problem with $\delta=0$ with the following substitutions: (1) changing the discount rate from $\gamma$ to $\gamma(1-\delta)$, (2) changing the expected growth rate in demand from $\bar{\mu}$ to $\bar{\mu} /(1-\delta)$, and (3) decreasing the cost of one unit of the capital good from 1 to $(1-\delta)$

\section{Proof of Proposition 4.}

The proof is by backwards induction and repeats the same steps as the proof of Proposition 2 . 


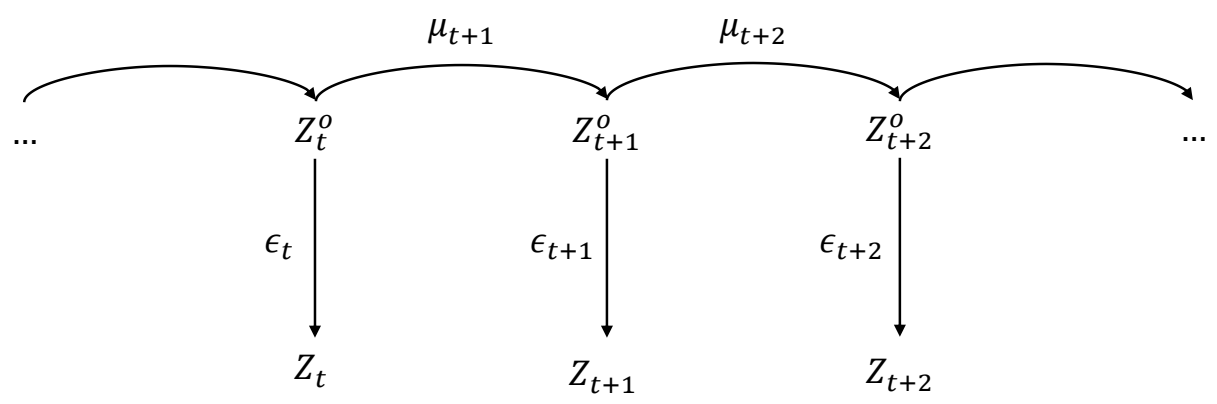

Figure 1: Time Evolution of the Stochastic Demand Shift Parameter

The value of the stochastic demand shift parameter in period $t+1$ is given by $Z_{t+1}=\epsilon_{t+1} Z_{t+1}^{o}$, where $\epsilon_{t+1}$ is a transitory shock and $Z_{t+1}^{o}$ is the permanent component of the demand shift parameter. Furthermore, $Z_{t+1}^{o}$ evolves according to: $Z_{t+1}^{o}=\mu_{t+1} Z_{t}^{o}$. 